\title{
In-situ aircraft observations of ice concentrations within clouds over the Antarctic Peninsula and Larsen Ice Shelf
}

\author{
D. P. Grosvenor ${ }^{1, *}$, T. W. Choularton ${ }^{1}$, T. Lachlan-Cope ${ }^{2}$, M. W. Gallagher ${ }^{1}$, J. Crosier ${ }^{1,3}$, K. N. Bower ${ }^{1}$, \\ R. S. Ladkin ${ }^{2}$, and J. R. Dorsey ${ }^{1}$ \\ ${ }^{1}$ University of Manchester, Centre for Atmospheric Science, SEAES, Manchester, UK \\ ${ }^{2}$ British Antarctic Survey, Cambridge, UK \\ ${ }^{3}$ National Centre for Atmospheric Science, University of Manchester, UK \\ * now at: Department of Atmospheric Science, University of Washington, Seattle, USA
}

Correspondence to: T. W. Choularton (choularton@manchester.ac.uk) and D. P. Grosvenor (daniel.p.grosvenor@gmail.com)

Received: 2 May 2012 - Published in Atmos. Chem. Phys. Discuss.: 13 July 2012

Revised: 19 October 2012 - Accepted: 20 November 2012 - Published: 3 December 2012

\begin{abstract}
In-situ aircraft observations of ice crystal concentrations in Antarctic clouds are presented for the first time. Orographic, layer and wave clouds around the Antarctic Peninsula and Larsen Ice shelf regions were penetrated by the British Antarctic Survey's Twin Otter aircraft, which was equipped with modern cloud physics probes. The clouds studied were mostly in the free troposphere and hence ice crystals blown from the surface are unlikely to have been a major source for the ice phase. The temperature range covered by the experiments was 0 to $-21^{\circ} \mathrm{C}$. The clouds were found to contain supercooled liquid water in most regions and at heterogeneous ice formation temperatures ice crystal concentrations (60 s averages) were often less than $0.071^{-1}$, although values up to $0.221^{-1}$ were observed. Estimates of observed aerosol concentrations were used as input into the DeMott et al. (2010) ice nuclei (IN) parameterisation. The observed ice crystal number concentrations were generally in broad agreement with the IN predictions, although on the whole the predicted values were higher. Possible reasons for this are discussed and include the lack of IN observations in this region with which to characterise the parameterisation, and/or problems in relating ice concentration measurements to IN concentrations. Other IN parameterisations significantly overestimated the number of ice particles. Generally ice particle concentrations were much lower than found in clouds in middle latitudes for a given temperature.

Higher ice crystal concentrations were sometimes observed at temperatures warmer than $-9^{\circ} \mathrm{C}$, with values of several per litre reached. These were attributable to sec-
\end{abstract}

ondary ice particle production by the Hallett Mossop process. Even in this temperature range it was observed that there were regions with little or no ice that were dominated by supercooled liquid water. It is likely that in some cases this was due to a lack of seeding ice crystals to act as rimers to initiate secondary ice particle production. This highlights the chaotic and spatially inhomogeneous nature of this process and indicates that the accurate representation of it in global models is likely to represent a challenge. However, the contrast between Hallett Mossop zone ice concentrations and the fairly low concentrations of heterogeneously nucleated ice suggests that the Hallet Mossop process has the potential to be very important in remote, pristine regions such as around the Antarctic coast.

\section{Introduction}

Antarctica has a landmass equal to almost $10 \%$ of the land area of Earth, and at 14.0 million $\mathrm{km}^{2}$ is approximately twice the size of Australia. Most clouds over Antarctica occur in air masses at coastal regions that are moister than the dry continental interior. Kay et al. (2012, hereafter K12) showed that various satellite cloud climatologies (CALIPSO, MISR, ISCCP) reveal that the Southern Ocean is one of the cloudiest places on Earth with extensive cloud cover at all longitudes. From CERES-EBAF satellite measurements K12 also showed that the clouds throughout much of this ocean produce a large negative annual mean Shortwave Cloud Forcing 
(SWCF; values as low $-95 \mathrm{~W} \mathrm{~m}^{-2}$ ) for the top of the atmosphere, which is larger in magnitude than the (positive) Longwave Cloud Forcing (LWCF; $\sim 25-35 \mathrm{~W} \mathrm{~m}^{-2}$ ). Thus, these clouds produce an overall cooling effect on Earth.

However, as well as being dependent on the cloud optical depth, SWCF is also dependent on the Solar Zenith Angle $\left(\theta_{0}\right.$, the angle between the Sun and a line perpendicular to the surface) and surface albedo. Increases in these latter two parameters cause SWCF to become less negative. Thus, the magnitude of SWCF tends to reduce towards Antarctica over the open ocean since $\theta_{0}$ tends to increase, as demonstrated in K12 for the TOA radiation balance and in Pavolonis and Key (2003, hereafter P03) for the surface. Over the ice covered landmass of the Antarctic continent, where both the surface albedo and $\theta_{0}$ tend to be high, SWCF is even less negative (P03) and reaches zero when there is no available sunlight in the winter months. $\mathrm{P} 03$ also demonstrated the diurnal variation of SWCF due to changes in $\theta_{0}$ throughout the day.

Relative to SWCF, P03 suggested that LWCF varies only slightly with latitude and season in the Southern Ocean and Antarctic region. Thus, when the magnitude of the SWCF is small, clouds act to warm the surface relative to clear skies. The results in P03 suggest that this is the case throughout almost the entire year at latitudes south of $75^{\circ} \mathrm{S}$.

The region of interest for this study is the Antarctic Peninsula (hereafter AP), which is a $\sim 1500 \mathrm{~km}$ long finger of land consisting of a high mountain ridge with tops over $2 \mathrm{~km}$ high. It is the northernmost part of Antarctica with its tip extending to $\sim 63^{\circ} \mathrm{S}$. The AP contains extensive ice shelf regions on its east side (the Larsen Ice Shelves). Between February and March 2002 the Larsen B ice shelf experienced a dramatic disintegration when an area of $3200 \mathrm{~km}^{2}$ was lost (Scambos, 2004). Crevasse propagation due to the weight of accumulated melt water is currently thought to have been the major factor in the 2002 break up, as well as in the break up of other ice shelves around the AP (Scambos et al., 2000, 2004; van den Broeke, 2005).

From over 2 yr of surface radiation measurements Kuipers Munneke et al. (2012) showed that most surface melting on the Larsen $\mathrm{C}$ ice shelf occurs in the daytime in the summer season, during cloud-free conditions and that the largest component to the melt energy was net downwelling SW radiation (see also King et al., 2008). Examination of the transition between a melting and non-melting period suggested that, despite a high surface albedo, increased cloud cover likely acted to reduce the net downwelling (SW+LW) surface radiation when considering the times of day at which melting occurred. For this reason, clouds over the Larsen and other ice shelves, as well as over sea-ice, are likely to be additionally important.

Surface processes in Antarctica may also be important in a global sense. Lubin et al. (1998) presented modelling evidence that changes to the local heating budget of Antarctica to changes in cloud properties might have global con- sequences through the altering of the latitudinal temperature gradient of the planet.

Given the very cold temperatures at Antarctica latitudes, ice phase processes will be important for many clouds there. A supercooled liquid cloud is likely to be more optically thick than a fully glaciated ice cloud, in part because ice particles will grow at the expense of water droplets due to the Bergeron-Findeisen process. This also leads to increased precipitation from the cloud, depleting the overall water mass and reducing its lifetime with consequent radiative effects. Shupe and Intrieri (2004) showed that Arctic clouds containing only ice generally produced a much lower magnitude of both SWCF and LWCF than liquid containing clouds, which is consistent with them having a lower optical depth.

Thus, understanding what affects the properties of clouds in the Antarctic region (e.g. phase, optical depth, etc.) is important as they are likely to have ramifications on both the local (i.e. surface) radiation balance and that of the planet. Despite this, Antarctic atmospheric processes remain poorly sampled, particularly in terms of clouds, due to its remote location and inhospitable environment. Manned surface stations provide the bulk of the observations, but these are sparse, particularly in the continental interior. Some stations are equipped with ground based radar and lidar for the long term observation of cloud, e.g. Bromwich et al. (2012). However, in-situ cloud microphysical observations of Antarctic clouds have only been made rarely, for very brief periods, and with limited instrumentation. In particular, studies of ice formation in Antarctic clouds have been very limited and this will be the focus of the present work.

\subsection{Ice in Antarctic clouds}

In the AP region only one in-situ cloud ice study of note has been published to date. Lachlan-Cope et al. (2001) describes the ground based sampling of an orographic cloud over the Avery Plateau using hand held formvar slide replicas. Ice crystals were photographed and counted under a microscope in order to calculate ice concentrations. Very large concentrations $\left(\sim 1201^{-1}\right)$ were estimated with very few droplets observed. At the cloud temperature sampled, $\left(-17.5^{\circ} \mathrm{C}\right)$, this was significantly higher than predicted using the Fletcher (1962) ice nuclei (IN) parameterization. It was suggested that blowing snow from the surface that subsequently evaporated may have acted as a source of IN upwind of the measurements. This is consistent with the suggestions made in Hara et al. (2011) and Ardon-Dryer et al. (2011), that aerosol emissions from ocean and surface ice by wind driven suspension processes would result in enhancement of aerosol concentrations in these size ranges making interpretation of surface sampled IN problematic.

Understanding of the relationship between ice and IN concentrations remains uncertain since it is often difficult to discriminate between observed cloud ice particle number concentrations activated through primary heterogeneous ice 
nucleation and those formed by secondary processes, without recourse to fast imaging spectrometers (e.g. Crosier et al., 2011). Furthermore, measurements of IN are difficult and only recently has there been a resurgence due to the development of new instruments (DeMott et al., 2011). Many insitu cloud observations have suggested inconsistencies between measured IN concentrations and in-cloud ice concentrations (e.g. Fridlind et al., 2007; Cooper, 1986) with the suggestion sometimes being made that (as yet) uncharacterized processes might be operating. However, the difficulties mentioned above, and the lack of laboratory evidence, make this difficult to substantiate.

One aim of the present study is to examine how representative different heterogeneous ice nuclei parameterizations e.g. those described by DeMott et al. (2010, hereafter $D 10$ ), Cooper (1986), Meyers et al. (1992) and Fletcher (1962), are for predicting ice crystal number concentrations for clouds prevalent in the AP and Larsen Ice Shelf regions. These schemes are all based upon measurements outside of the Antarctic region.

It was demonstrated in $D 10$ that IN concentrations are correlated with concentrations of large $(D>0.5 \mu \mathrm{m})$ aerosol particles, as well as being negatively corrlelated with temperature. Due to the lack of anthropogenic aerosol sources over the continent, the coastal regions of Antarctica, such as the AP, show significantly lower aerosol concentrations than most other maritime regions (Hogan, 1986) and on the whole can be thought of as a relatively pristine environment. Combined with the results of $D 10$ this might indicate an expectation of low IN concentrations in this region, although it should be pointed out that the Hogan (1986) measurements were of small Aitken mode aerosols rather than the large sized aerosols thought to control IN. However, evidence for the influence of long range transport of anthropogenic aerosols (fossil fuel burning) from South America on the AP sector (to as far east as $2.5^{\circ} \mathrm{E}$ ) was provided by Barbante et al. (1998). Other influences have also been identified by various researchers including Fiebig et al. (2009) and Hara et al. (2010), biomass burning; and McConnell et al. (2007), dust transport due to desertification. The latter study showed a doubling of alumino-silicate concentrations over the 20th century at an AP site and suggested a link to increased levels of desertification in South America.

Thus, Antarctic IN concentrations may show some anthropogenic influence and efforts to estimate them are likely to be complicated by this. Unfortunately, there have been very few observations of IN concentrations made in Antarctica and they have generally been with only surface based instrumentation. Kumai (1976) used electron diffraction analysis of residual central nuclei following the sublimation of 93 individual snowflakes collected at the South Pole to interpret IN type and possible sources. Interpretation of the results could have been confounded by the fact that many of the snowflakes contained particulate matter other than just the central nucleus due to efficient aerosol scavenging by the snowflakes. It was concluded, however, that Antarctic IN populations were likely dominated by clay particles arising from long range transport.

Bigg (1990) reviewed six different IN datasets from high southern latitudes $\left(>60^{\circ} \mathrm{S}\right)$ collected between 1961 and 1988. Samples were collected in different regions, e.g. from ships close to the Antarctic Peninsula as well as surface sites. However, the measurement techniques used varied across the datasets. Reported mean IN concentrations ranged from $2 \times 10^{-4}$ to $0.21^{-1}$ (at $T=-15^{\circ} \mathrm{C}$ ) with a suggestion that IN concentrations had decreased over the period.

In a more recent study, Ardon-Dryer et al. (2011) processed aerosol filters sampled at the South Pole (12 in total, 3 collected from a balloon and 9 from a laboratory rooftop). Solution droplets from the samples were tested in a freezing chamber to determine their activation temperatures; ice onset occurred at $\sim-18^{\circ} \mathrm{C}$. Elemental analysis subsequently verified that the composition of the aerosol was similar to that of mineral dusts collected from the Patagonian deserts in South America. Estimated IN concentrations ranged from 0.1 to $531^{-1}$ with a mean of $11^{-1}$ at $T=-23^{\circ} \mathrm{C}$. However, as with many similar near-ground studies, the concentrations were observed to correlate with wind speed, suggesting the filter samples were influenced by a local surface source subject to suspension processes.

In such a pristine environment as Antarctica it is possible that biogenic IN could play a relatively more important role, particularly on a seasonal basis. Alpert et al. (2011) and Knopf et al. (2011) showed that the presence of certain marine phytoplankton caused droplets to freeze at temperatures warmer than homogeneous freezing temperatures and it has been suggested that there are some bacteria that can nucleate ice at temperatures as warm as $-2^{\circ} \mathrm{C}$ (see Möhler et al., 2007; Hoose et al., 2010). However, concentrations of biological IN in worldwide snowfall have been found to be lowest in Antarctica compared to elsewhere (Christner et al., 2008) and also Junge and Swanson (2008) found that bacteria common in sea ice were not particularly efficient at nucleating ice at relevant temperatures.

Given these previous measurements and the general marine character of Antarctic aerosols, along with only the occasional influx of aerosol associated with non-ice covered land areas, IN concentrations in the AP region of this study would be generally expected to be fairly low, particularly as IN are generally thought to be associated with clay mineral and dust particles (e.g. Kumai, 1976; DeMott et al., 2003).

\subsection{Airborne cloud measurements in Antarctica}

In this paper we describe airborne in-cloud sampling of clouds in the Antarctic Peninsula region. This is the first time that clouds have been directly sampled by aircraft in Antarctica since the two flights in November 1980 described in Saxena and Ruggiero (1990) when clouds were penetrated over Ross Island, located near the Ross Ice Shelf. Liquid water 


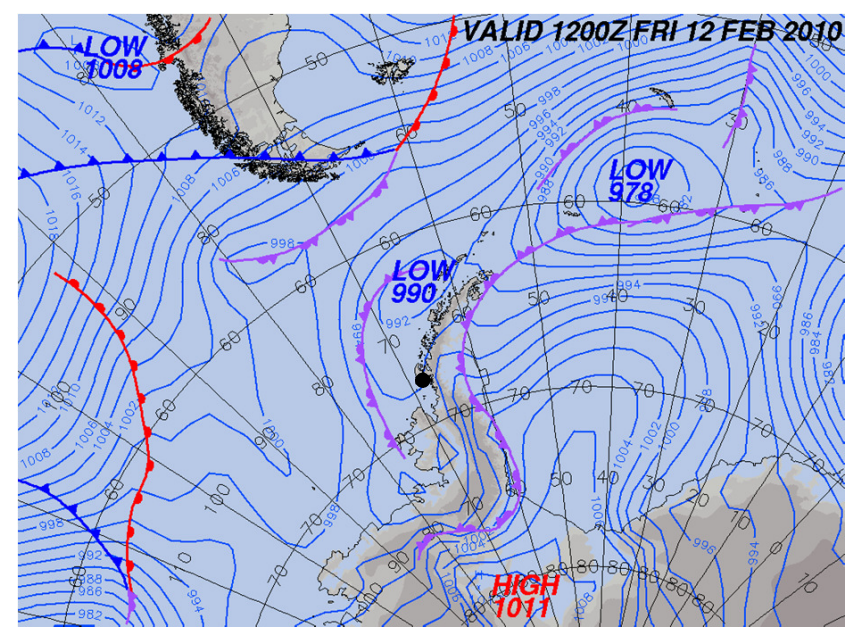

Fig. 1. The surface pressure chart for flight \#104 on 12 February 2010, 12:00 UTC. The location of the British Antarctic Survey Rothera Station is also shown on the map with the black circle.

contents (LWC) ranging from $0.06-0.18 \mathrm{~g} \mathrm{~m}^{-3}$ were reported for clouds with base temperatures of -18.6 and $-5.3{ }^{\circ} \mathrm{C}$. The results suggested a lack of glaciation. Droplet properties were measured using a Particle Measuring Systems Forward Scattering Spectrometer Probe (FSSP-100) and it was found that mean cloud droplet diameters ranged between 9.2 and $13.5 \mu \mathrm{m}$ with concentrations in the range $33-101 \mathrm{~cm}^{-3}$ (with an average of $64 \mathrm{~cm}^{-3}$ ) that are typical of other maritime locations. In the same study, analysis of cloud water samples suggested that the main source of CCN was likely to be either sea-salt or sulphate, with biogenic marine sulphate suggested as being responsible for the observed higher than expected cloud acidity ( $\mathrm{pH}$ 5.7-6.2).

However, there was no means of quantifying ice or precipitation particles and hence the ice process sampling described in the present manuscript represents the first airborne in-situ sampling of ice with modern imaging spectrometers in Antarctic clouds.

In February 2010, 14 in-situ cloud sampling flights were conducted from the British Antarctic Survey Rothera station $\left(67.6^{\circ} \mathrm{S}, 68.1^{\circ} \mathrm{W}\right)$ on the Antarctic Peninsula, shown in Fig. 1. We describe five cloud case studies covering a range of temperatures, both with and without secondary ice multiplication processes occurring, and compare observed ice crystal concentrations with those estimated using typical IN parameterisations.

\section{Instrumentation}

A Twin Otter aircraft, described by King et al. (2008), was fitted with liquid and ice cloud microphysical instruments. In addition to meteorological state parameters and 3-D wind and turbulence measurements (King et al., 2008), the air- craft was equipped with a Droplet Measurement Technologies (DMT) Cloud Aerosol and Precipitation Spectrometer (CAPS), described in detail by Baumgardner et al. (2001).

Briefly, CAPS consists of several different instruments including: (1) a Mie scattering Cloud Aerosol Spectrometer (CAS), which measures particle number size distributions in the range $0.6-50 \mu \mathrm{m}$ diameter. This was calibrated to size liquid water droplets using NIST standard glass and latex beads, although it will also detect coarse aerosol and small ice particles; (2) a Cloud Imaging Probe (CIP), which is able to record 2-D images of particles with sizes between 12.5 and $1612.5 \mu \mathrm{m}$ using a 64 element photodiode array with a resolution of $25 \mu \mathrm{m}$; and (3) a DMT hotwire sensor, which provides a measure of the total cloud liquid water content (LWC).

The CAPS instrument has seen many refinements over the last decade, e.g. the CAS instrument in this study was not fitted with a flow-straightener shroud as in earlier models since previous studies suggested it significantly increased measurement artefacts due to droplet shattering and ice particle breakup (DMT, personal communication, 2010 and Korolev et al., 2011). Shattered particles in the CIP dataset were identified and removed prior to analysis using software developed at the University of Manchester, as used in Crosier et al. (2011). Some small modifications were made to the rejection criteria, which are detailed in Appendix A1. The CIP was not fitted with anti-shatter tips (Korolev et al., 2011), as these were not available at the time.

Discrepancies between hotwire sensor LWC measurements and those calculated from integrated droplet size spectra can be significant (depending on cloud conditions) mainly due to droplet size dependent collection efficiency limitations of the hot-wire sensor and sample volume issues with Mie scattering spectrometers (e.g Baumgardner et al., 2001; Painemal and Zuidema, 2011; DMT, 2011). In this campaign the LWC calculated using the CAS was found to be higher than that from the hotwire probe by up a factor of 2.5 , which is much higher than the magnitude of the discrepancy generally reported in the literature. Post campaign comparisons to another CAS instrument suggested an overcounting problem at the larger size range of the CAS spectrum and thus only the hotwire instrument is used to quantify LWC here.

In one of the flights discussed in this paper (\#102) some very high ice number concentrations were reported. Study of the aircraft flight track suggested that this was almost certainly aircraft induced ice nucleation, which likely occurred due to the local cooling effect of the aircraft propellers (Heymsfield et al., 2010; Westbrook and Davies, 2010). The nature of the flight track in this case made contamination of the sampled clouds more likely since the plane tended to sample clouds, turn around, and then sample clouds downwind, all at a similar altitude. This highlights that care should be taken to avoid this through appropriate flight track design. However, such contamination was ruled out for any of the 
other flights reported in this paper through careful examination of the flight tracks.

\subsection{Ice particle data analysis}

As the CIP instrument provided the key observations of ice crystal number concentrations we briefly describe the sampling issues associated with it in Appendix A2. Full details of the operating principles of the CIP instrument are described by Baumgardner et al. (2001) and in DMT instrument documentation (DMT, 2011).

CIP ice concentration data were initially integrated over $1 \mathrm{~s}$. This corresponds to an effective sample volume of $\sim 10.4 \mathrm{~L}$ at the BAS Twin Otter aircraft speed of $65 \mathrm{~m} \mathrm{~s}^{-1}$ when using the "centre-in" (see Appendix A2) analysis (for $D>212 \mu \mathrm{m}$ ), i.e. corresponding to a minimum spatial scale of $65 \mathrm{~m}$. Standard Poisson counting statistics were assumed when estimating the error in measured particle concentrations for a specified confidence interval and to estimate a minimum detectable concentration. For a $1 \mathrm{~s}$ sample the latter equates to an ice concentration of $\sim 0.31^{-1}$. In the following analyses standard error bars (67\% Poisson confidence range) are used. In this work it was often necessary to average ice concentrations over longer timescales in order to reduce the Poisson counting errors. $60 \mathrm{~s}$ values are usually quoted since this generally represents the minimum averaging time required to give Poisson counting errors of $30 \%$ or less when ice concentrations are larger than $0.021^{-1}$. The mean error for concentrations lower than this was $37 \%$ with a maximum of $45 \%$ (flight segment 104-i3 in Table 1). Calibration of the CIP probe was performed though laboratory tests using spinning disks etched with ice crystal and droplet images of known sizes that were passed through the instrument sample volume at different depth of field distances.

The CIP-25 probe is probably unable to distinguish droplets from ice crystals for particle sizes $<\sim 112.5 \mu \mathrm{m}$ due to its $25 \mu \mathrm{m}$ resolution (e.g. see Avramov et al., 2011). Therefore, ice concentrations are only counted for crystals that are larger than this size, which means that newly nucleated ice particles will be undetected in this study. However, in a mixed phase cloud ice particles grow fairly rapidly so that they soon become detectable.

Pruppacher and Klett (1997, hereafter P07) give estimates of ice growth rates through diffusion that suggests a growth time of 50-300 s to reach the detection size, depending on habit. P07 and Mitchell and Heymsfield (2005) give estimates of the fall speeds of different types of ice particle as a function of diameter and show that particles of diameter $112.5 \mu \mathrm{m}$ have a fall speed of below $\sim 30 \mathrm{~cm} \mathrm{~s}^{-1}$. Thus, newly nucleated ice crystals will fall a maximum distance of around $90 \mathrm{~m}$ during growth to the detectable size, during which a temperature difference of $<\sim 1$ degree would be experienced. Therefore, ice is theoretically detectable in conditions very close to those of its nucleation location.
For condensation freezing, most ice nucleation likely occurs nearer to the top of liquid layers due to the decrease of temperature with height and so it is these regions where the problem might be expected to be the worst. However, since in this study measurements were made at various depths relative to cloud top (including below cloud base), ice concentrations representative of that nucleated in the uppermost regions of cloud were likely sampled lower down in the clouds.

Finally, an important point to note is that all data in this manuscript (ice, aerosol and liquid water concentrations) have been scaled to STP values, in keeping with $D 10$ and other studies.

\section{Observation results}

The five cloud sampling flights considered in this study took place between 6 and 12 February 2010. The results from these flights are summarised in Tables 1 and 2. For Table 1 the intention was to list periods in which ice was present continuously, so that the mean ice concentrations are meaningful. In order to do this, periods were chosen based on the criteria of whether the $300 \mathrm{~s}$ window averaged ice concentration was larger than $1 \times 10^{-3} 1^{-1}$ and that contained no icefree periods longer than $90 \mathrm{~s}$. Since all of the periods chosen in this manner were longer than $5 \mathrm{~min}$ in duration, the mean values represent averages over periods with the sustained presence of ice particles. No isolated regions of significant ice concentrations were excluded by this process. Similarly, for Table 2 continuous periods were chosen for which the $30 \mathrm{~s} \mathrm{LWC} \mathrm{was} \mathrm{larger} \mathrm{than} 0.075 \mathrm{~g} \mathrm{~m}^{-3}$, which contained no ice particles and were at least $45 \mathrm{~s}$ in duration. The regions have been segregated into periods of different cloud types according to the following categories: (i) orographic/lee wave clouds; (ii) layer clouds observed over the Larsen C Ice Shelf; and (iii) layer clouds in which the Hallett-Mossop process (Hallett and Mossop, 1974) was observed to be operating.

All five flights are described below, although flight \#104 is described in greater detail in order to demonstrate the typical orographic and Larsen Ice Shelf cloud sampling strategies employed. Information on the synoptic situation, which may be helpful to place the microphysical measurements into a meteorological context, is provided in Appendix B.

The aircraft flew over the Larsen Ice Shelf on flight \#s 99, 101 and 104, which involved crossing the ridge of the AP. This was typically achieved with a sharp ascent to around $4 \mathrm{~km}$, followed by a descent towards the ice shelf surface after crossing the ridge. This was repeated on the way back to Rothera and so allowed for two sets of sampling of the orographic cloud that was always observed to be present over the ridge. For flights 101 and 104 the airflow across the AP was roughly from east to west, whereas generally the wind across the AP ridge is west to east, which was approximately the case for flight 99. 
Table 1. Summary of the properties of periods of the different flights in which sustained ice was detected. See the text for details on the criteria for identifying these periods. The table has been split into periods of orographic or wave cloud, cloud observed over the Larsen $\mathrm{C}$ Ice Shelf and cloud observed in the Hallett Mossop temperature range.

\begin{tabular}{|c|c|c|c|c|c|c|c|}
\hline $\begin{array}{l}\text { Flight and } \\
\text { section no. }\end{array}$ & Time & $\begin{array}{l}\text { Temp range } \\
\left({ }^{\circ} \mathrm{C}\right)\end{array}$ & $\begin{array}{c}\text { Mean } \\
\text { temp }\left({ }^{\circ} \mathrm{C}\right)\end{array}$ & $\begin{array}{l}\text { Mean ice conc } \\
\left(\left(^{-1}\right)\right.\end{array}$ & $\begin{array}{c}\text { Max/stddev } \\
60 \text { s ice conc }\left(1^{-1}\right)\end{array}$ & $\begin{array}{l}\text { Temp of } \\
\text { max conc } \\
\left({ }^{\circ} \mathrm{C}\right)\end{array}$ & $\begin{array}{l}\text { Mean/max/ } \\
\text { stddev LWC } \\
\left(\mathrm{g} \mathrm{m}^{-3}\right)\end{array}$ \\
\hline \multicolumn{8}{|c|}{ Orographic/Lee wave cloud } \\
\hline 99-i1 & $14: 22: 00$ to $14: 23: 51$ & -14.4 to -14.8 & -14.6 & $0.011 \pm 0.004$ & $0.014 \pm 0.006 / 0.002$ & -14.5 & $0.01 / 0.03 / 0.01$ \\
\hline $99-\mathrm{i} 2$ & $16: 41: 17$ to $16: 45: 02$ & -13.2 to -16.0 & -14.1 & $0.007 \pm 0.002$ & $0.015 \pm 0.005 / 0.004$ & -14.4 & $0.0 / 0.0 / 0.0$ \\
\hline $99-\mathrm{i} 3$ & $16: 46: 56$ to $16: 49: 46$ & -12.8 to -14.3 & -13.8 & $0.027 \pm 0.005$ & $0.040 \pm 0.009 / 0.008$ & -14.2 & $0.0 / 0.0 / 0.0$ \\
\hline 101-i1 & $13: 01: 05$ to $13: 15: 46$ & -7.3 to -15.9 & -11.0 & $0.06 \pm 0.003$ & $0.22 \pm 0.03 / 0.06$ & -10.8 & $0.03 / 0.10 / 0.02$ \\
\hline $101-\mathrm{i} 2$ & $13: 19: 05$ to $13: 40: 04$ & -11.1 to -19.4 & -16.6 & $0.073 \pm 0.003$ & $0.15 \pm 0.02 / 0.035$ & -12.4 & $0.04 / 0.34 / 0.05$ \\
\hline $101-\mathrm{i} 3$ & $15: 10: 56$ to $15: 16: 29$ & -7.9 to -11.6 & -9.8 & $0.011 \pm 0.002$ & $0.023 \pm 0.008 / 0.007$ & -10.2 & $0.0 / 0.0 / 0.0$ \\
\hline $102-\mathrm{i} 1$ & $20: 38: 02$ to $20: 42: 51$ & -9.3 to -14.5 & -11.7 & $0.019 \pm 0.003$ & $0.037 \pm 0.009 / 0.008$ & -9.8 & $0.12 / 0.35 / 0.08$ \\
\hline $102-\mathrm{i} 2$ & $20: 48: 35$ to $20: 56: 26$ & -9.8 to -13.1 & -11.1 & $0.032 \pm 0.003$ & $0.16 \pm 0.02 / 0.044$ & -10.8 & $0.06 / 0.25 / 0.06$ \\
\hline $102-\mathrm{i} 3$ & $21: 13: 23$ to $21: 16: 12$ & -8.6 to -10.7 & -9.8 & $0.013 \pm 0.003$ & $0.030 \pm 0.008 / 0.01$ & -10.2 & $0.03 / 0.05 / 0.01$ \\
\hline $102-\mathrm{i} 4$ & $21: 33: 31$ to $21: 41: 16$ & -9.6 to -12.7 & -11.3 & $0.013 \pm 0.002$ & $0.059 \pm 0.012 / 0.015$ & -11.6 & $0.05 / 0.12 / 0.03$ \\
\hline 104-i1 & $18: 56: 18$ to $19: 16: 48$ & -5.2 to -20.9 & -13.5 & $0.039 \pm 0.002$ & $0.11 \pm 0.02 / 0.03$ & -17.4 & $0.09 / 0.39 / 0.10$ \\
\hline $104-\mathrm{i} 2$ & $21: 36: 16$ to $21: 43: 11$ & -17.7 to -20.4 & -19.5 & $0.016 \pm 0.003$ & $0.053 \pm 0.013 / 0.015$ & -20.2 & $0.16 / 0.51 / 0.17$ \\
\hline \multicolumn{8}{|c|}{ Cloud layers over Larsen C } \\
\hline 99-i4 & $15: 19: 02$ to $15: 26: 06$ & -7.0 to -15.6 & -12.2 & $0.007 \pm 0.002$ & $0.017 \pm 0.007 / 0.005$ & -13.8 & $0.02 / 0.08 / 0.02$ \\
\hline 99-i5 & $15: 27: 44$ to $15: 56: 59$ & -11.7 to -16.9 & -15.8 & $0.007 \pm 0.001$ & $0.020 \pm 0.007 / 0.004$ & -16.5 & $0.08 / 0.19 / 0.06$ \\
\hline $104-\mathrm{i} 3$ & $19: 42: 11$ to $19: 45: 55$ & -10.4 to -18.3 & -14.5 & $0.008 \pm 0.002$ & $0.012 \pm 0.005 / 0.003$ & -17.7 & $0.02 / 0.22 / 0.06$ \\
\hline $104-\mathrm{i} 4$ & $20: 53: 36$ to $21: 06: 16$ & -10.3 to -16.5 & -15.1 & $0.011 \pm 0.002$ & $0.032 \pm 0.010 / 0.007$ & -13.4 & $0.0 / 0.05 / 0.01$ \\
\hline \multicolumn{8}{|c|}{ Hallett Mossop Zone ice } \\
\hline $100-\mathrm{i} 1$ & $13: 39: 11$ to $13: 45: 38$ & -0.4 to -0.9 & -0.6 & $0.52 \pm 0.02$ & $1.28 \pm 0.06 / 0.38$ & -0.7 & $0.01 / 0.04 / 0.01$ \\
\hline $100-\mathrm{i} 2$ & $14: 04: 29$ to $14: 11: 36$ & -1.0 to -2.4 & -2.1 & $1.14 \pm 0.02$ & $3.44 \pm 0.11 / 1.01$ & -2.3 & $0.01 / 0.04 / 0.01$ \\
\hline $100-\mathrm{i} 3$ & $14: 29: 57$ to $14: 39: 07$ & -4.2 to -6.6 & -4.6 & $1.47 \pm 0.02$ & $6.26 \pm 0.15 / 1.78$ & -4.3 & $0.06 / 0.25 / 0.06$ \\
\hline $100-\mathrm{i} 4$ & $14: 44: 12$ to $14: 52: 06$ & -5.2 to -6.1 & -5.8 & $0.90 \pm 0.02$ & $4.77 \pm 0.12 / 1.28$ & -5.9 & $0.19 / 0.31 / 0.06$ \\
\hline $100-\mathrm{i} 5$ & $15: 17: 17$ to $15: 18: 30$ & -4.8 to -5.8 & -5.3 & $0.050 \pm 0.011$ & $0.058 \pm 0.013 / 0.012$ & -5.6 & $0.09 / 0.22 / 0.07$ \\
\hline $100-\mathrm{i} 6$ & $15: 26: 12$ to $15: 28: 00$ & -3.5 to -5.7 & -4.7 & $0.040 \pm 0.008$ & $0.067 \pm 0.014 / 0.028$ & -5.2 & $0.08 / 0.23 / 0.08$ \\
\hline 104-i5 & $19: 56: 11$ to $20: 01: 24$ & -1.9 to -4.0 & -2.6 & $0.098 \pm 0.007$ & $0.37 \pm 0.03 / 0.12$ & -2.3 & $0.10 / 0.26 / 0.08$ \\
\hline 104-i6 & $20: 04: 41$ to $20: 15: 17$ & -2.1 to -4.9 & -2.8 & $0.33 \pm 0.01$ & $2.70 \pm 0.10 / 0.63$ & -2.3 & $0.09 / 0.45 / 0.14$ \\
\hline
\end{tabular}

\subsection{Flight \#104, 12 February 2010}

Visible and infra-red satellite imagery, Figs. 2 and 3, respectively, show cloud associated with an occluded front (Fig. 1, see Appendix B for a description). A detail of the aircraft flight track is superimposed on the satellite images. Numbered markers on these figures show the location of points of interest that will be referred to subsequently.

During the flight the aircraft traversed over the Antarctic Peninsula ridge from west to east at an altitude of $\sim 4 \mathrm{~km}$. The wind direction was from $\mathrm{N}$ to $\mathrm{NE}$ and wave clouds were observed downwind of the ridge in this wind direction (see Fig. 2). Ice and supercooled liquid clouds were sampled in this region (between markers 1 and 2). The aircraft then made a descent towards the surface of the Larsen C Ice Shelf and conducted multiple straight and level flight legs over the ice shelf during which several layers of cloud were encountered (markers 3-7). On the return over the AP the same orographic cloud was again sampled (between markers 8 and
9). Figure 4 shows a 3-D view of the aircraft flight track in which locations of regions of supercooled water and ice particles have been highlighted.

\subsubsection{Orographic cloud over the Antarctic Peninsula}

The region between markers 1 and 2 on Figs. 2 and 3 was one where the aircraft was sampling cloud whilst ascending up the west slope of the AP and traversing some way over the mountain ridge. It coincides with the period 104i1 in Table 1 (18:56:18 to 19:16:48 UTC). The temperature reached as low as approximately $-21^{\circ} \mathrm{C}$ (Fig. 5a). At $-19^{\circ} \mathrm{C}$ large temperature fluctuations were observed close to the top of the mountain ridge, which were likely due to gravity waves. During 104-i1, a maximum LWC of $0.39 \mathrm{~g} \mathrm{~m}^{-3}$ was observed (Fig. 5b) and mean ice particle concentrations were $\sim 0.039 \pm 0.0021^{-1}$, with a maximum $60 \mathrm{~s}$ value of $\sim 0.11 \pm 0.021^{-1}$. 


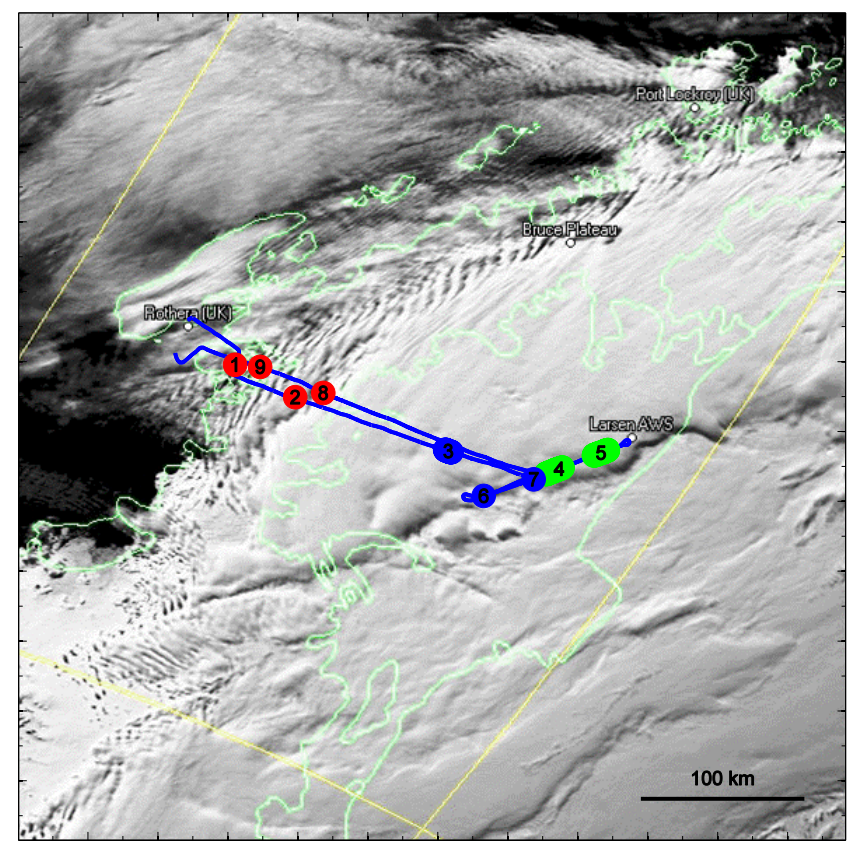

Fig. 2. AVHRR visible satellite image coincident with flight 104 (12 February 2010) showing the aircraft flight track. Positions of interest along the track are marked with numbered points, which are referred to in the text. The red markers denote regions of orographic cloud, the blue is stratified cloud over the Larsen Ice Shelf and green denotes Hallett Mossop temperature cloud.

Figure 6a-c show CIP 2-D images of the cloud particles sampled in the orographic cloud. The first image strip shows the period 19:02:50-19:09:28 (Fig. 6a), during which the aircraft was ascending. It shows mainly ice crystals, dendrites and aggregates between -11 and $-16.5^{\circ} \mathrm{C}$, with the large size and lack of LWC during the first part of the ascent suggesting that precipitation from cloud above was being sampled. The MODIS Cloud Top Temperature (CTT) field (Fig. 3) shows a cloud with a top at around $-20^{\circ} \mathrm{C}$ located over the ridge, which also extends over the location of the ascent and over Larsen C. However, there is also a small band of colder cloud to the west (CTT of around $\left.-43^{\circ} \mathrm{C}\right)$. Given the wind direction, though, it seems unlikely that that this will have contributed to the ice sampled during the ascent.

There followed a sharp transition to mixed phase cloud (end part of Fig. 6a and b) and then to mostly supercooled water cloud, Fig. 6c. A very few large, smooth ellipsoidal particles (e.g. Fig. 6b) that were likely rain drops were also observed. The presence of precipitation sized liquid particles at supercooled temperatures without the presence of a warm layer above (i.e. ruling out melted ice) has been observed several times before and is generally associated with low IN and ice crystal concentrations (Huffman and Norman, 1988; Cober et al., 1996; Kajikawa et al., 2000).

Orographic cloud was sampled in the same region and at approximately the same altitude on the return leg $2.5 \mathrm{~h}$ later

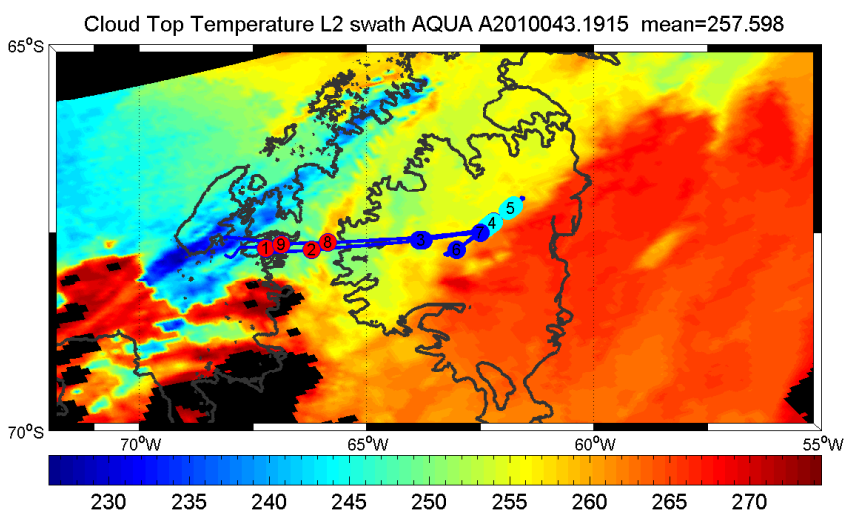

Fig. 3. MODIS satellite cloud top temperature (K) from 19:15 UTC on the day of flight 104 with the flight track and markers as for Fig. 2 except that the Hallett Mossop markers (4 and 5) are now a different colour for clarity.

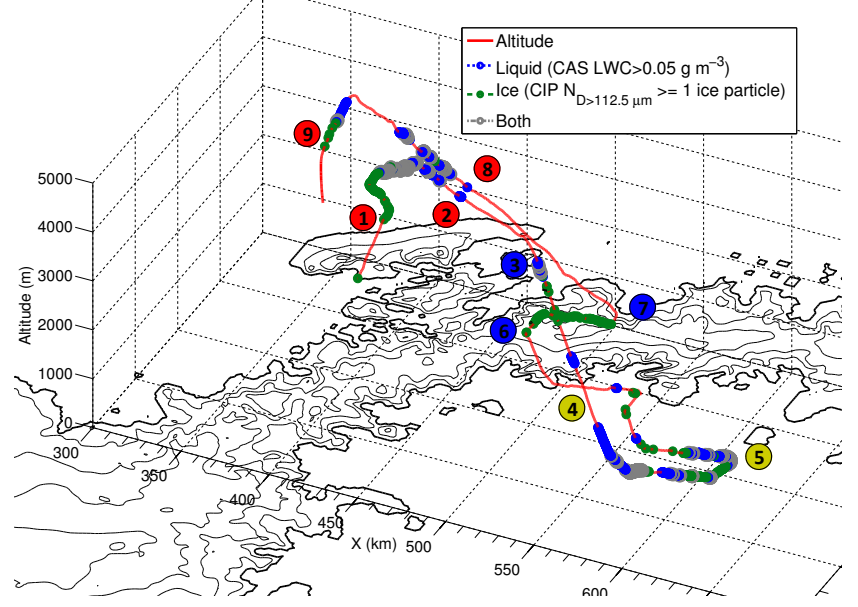

Fig. 4. 3-D isometric view of flight \#104 looking approximately from the east over the Antarctic Peninsula. The contours represent $500 \mathrm{~m}$ terrain height steps; blue symbols without numbers (see the legend) show regions where liquid water was detected with CAS LWC values $>0.05 \mathrm{~g} \mathrm{~m}^{-3}$; green symbols show regions where at least one ice particle with $D>112.5 \mu \mathrm{m}$ was detected by the CIP per second; and grey symbols represent mixed phase regions (i.e. both the above criteria met). The coloured symbols with numbers inside indicate the approximate positions of the markers in Figs. 2 and 3 .

(between markers 8 and 9 in Figs. 2 and 3, period 104-i2 in Table 1) at temperatures between -17.7 and $-20.4^{\circ} \mathrm{C}$, by which time the observed maximum LWC had increased to $0.51 \mathrm{~g} \mathrm{~m}^{-3}$ and maximum ice concentrations, at $0.05 \pm$ $0.011^{-1}$, were significantly lower than during the first mountain traverse. The number of raindrop-like CIP images (similar to those highlighted in Fig. 6b, but not shown here) increased significantly suggesting that more supercooled precipitation had been generated by this stage. 
(a)

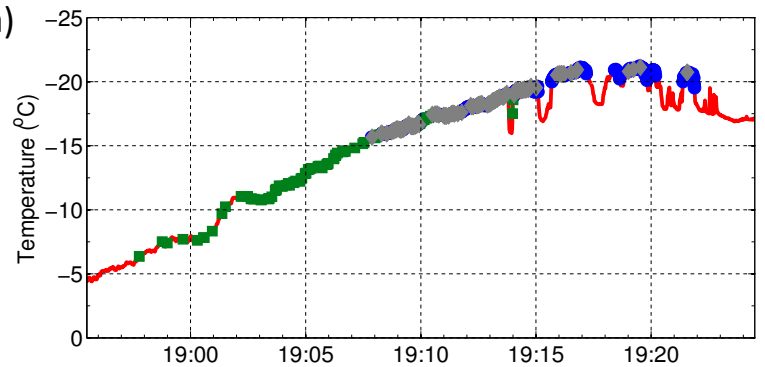

(b)

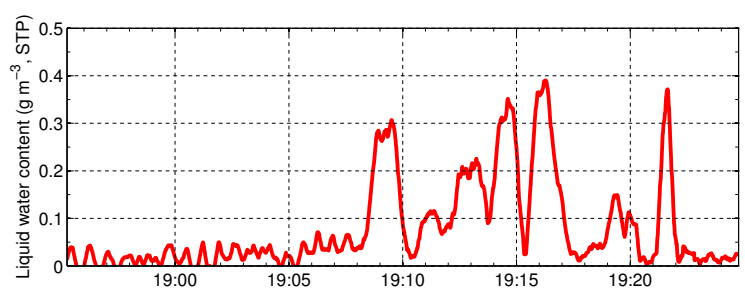

(c)

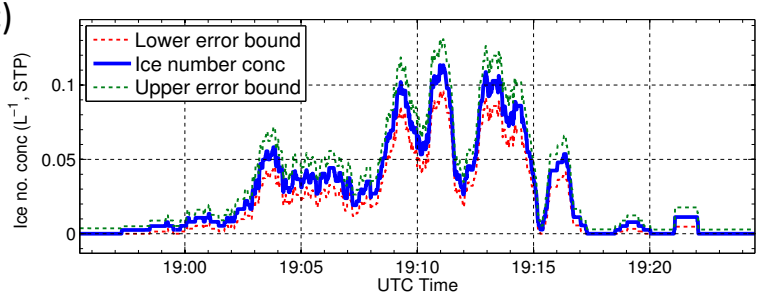

Fig. 5. Measurements made during flight \#104 as the aircraft ascended over the Antarctic Peninsula ridge. (a) - Temperature; (b) $30 \mathrm{~s}$ moving mean window liquid water content from the hotwire probe; (c) -60 s moving window mean ice number concentrations with lower and upper Poisson error bounds. The symbols in (a) show: ice only regions (green); water only (blue) and mixed phase regions (grey), as in Fig. 4.

Further along the outward bound mountain traverse a region of LWC was observed that contained no detectable ice (period 104-L1 in Table 2, 19:25:31 to 19:26:16). The maximum $30 \mathrm{~s} \mathrm{LWC}$ was $0.26 \mathrm{~g} \mathrm{~m}^{-3}$ with a mean of $0.18 \mathrm{~g} \mathrm{~m}^{-3}$ and temperatures ranged between -17.2 and $-20.8^{\circ} \mathrm{C}$. Another two liquid water only regions at cold temperatures were observed in this region (periods 104-L2 and 104-L3 in Table 2), with maximum LWCs of 0.41 and $0.34 \mathrm{~g} \mathrm{~m}^{-3}$, respectively. The low temperatures in periods 104-L1, 104-L2 and 104-L3 make it surprising that no ice was detected given the prevalence of liquid water available to allow condensation, immersion and contact freezing. This could indicate a lack of IN, or it is possible that ice could have been formed, but that it was below the lower size cutoff for ice detection for the CIP instrument that was imposed in this study $(112.5 \mu \mathrm{m})$.

As discussed in Sect. 2.1 any nucleated ice would only remain undetectable for a short distance $(\sim 90 \mathrm{~m})$ below its nucleation height, which would likely be nearer to the top of the liquid layer. The fact that the ice-free region of 104-L3 extended over a depth of $414 \mathrm{~m}$ suggests that it is more likely that a lack of IN was responsible for the lack of ice observed in that case. For 104-L1 and 104-L2 the liquid regions were only sampled over depths of 30 and $14 \mathrm{~m}$, respectively, and so it is possible that the sampling only occurred very near to cloud top.

\subsubsection{Stratus cloud over the Larsen C Ice Shelf}

After the aircraft had crossed the Peninsula ridge it descended on the east side towards the Larsen C Ice Shelf where cloud had formed into 3 distinct layers. On subsequent descent through these layers a sharp temperature inversion was observed at $3.7 \mathrm{~km}$ altitude and immediately below this was a cloud layer located between -16.5 and $-18.5^{\circ} \mathrm{C}$, with its base at $3.4 \mathrm{~km}$ (marker 3 in Figs. 2 and 3, period 104-i3 in Table 1). Supercooled water was detected with peak values of LWC of $0.22 \mathrm{~g} \mathrm{~m}^{-3}$ with very low concentrations of ice $\left(60 \mathrm{~s}\right.$ values of $\left.<0.0121^{-1}\right)$. The second cloud layer lay between 2.1 and $2.2 \mathrm{~km}\left(T=-7.5\right.$ to $\left.-8.5^{\circ} \mathrm{C}\right)$ beneath a weaker temperature inversion, with peak LWCs of $\sim 0.12 \mathrm{~g} \mathrm{~m}^{-3}$. This cloud contained no detectable ice and there was no evidence detected of ice seeding from the layer above. Finally, the third layer was observed between $1.15 \mathrm{~km}$ and $0.37 \mathrm{~km}\left(T=-6\right.$ to $\left.-2{ }^{\circ} \mathrm{C}\right)$. This layer was again situated below a further weak temperature inversion, however, unlike the others, it exhibited strong evidence of secondary ice multiplication occurring via the Hallett Mossop pathway. This "Hallett Mossop active layer" (referred to subsequently as a HM layer), will be discussed in greater detail in the next section.

On the ascent back to the $4 \mathrm{~km}$ level, on the return to Rothera, the aircraft again sampled the upper cloud layer but at a slightly lower altitude, $3.25-3.5 \mathrm{~km}$, and $40 \mathrm{~km}$ southeast of the original sampling location. Figure 3 suggests that this cloud (between markers 6 and 7, period 104-i4) was closer to the edge of the upper cloud layer. The inversion above the cloud layer had persisted, but the LWC was significantly lower, $<0.06 \mathrm{~g} \mathrm{~m}^{-3}$. Maximum ice concentrations were slightly higher than previously, $\left(\sim 0.032 \pm 0.011^{-1}\right)$. This might suggest that liquid water had been removed by evaporation driven by the entrainment of dry air at the cloud edges, or via the Bergeron-Findeisen process.

\subsubsection{The Hallett Mossop layer}

The lowest cloud layer was observed between $1.15 \mathrm{~km}$ and $0.375 \mathrm{~km}$, but likely extended down to the surface according to reports by the aircraft observers. The temperature during this phase of the flight is shown in Fig. 7. Measurements near the top of this layer $\left(1.12 \mathrm{~km}, T=-6^{\circ} \mathrm{C}\right)$ revealed the presence of a supercooled liquid layer, with maximum LWC values of $0.15 \mathrm{~g} \mathrm{~m}^{-3}$. A subsequent straight and level sampling run at lower levels $(0.375 \mathrm{~km}, T=-2$ to $-2.5^{\circ} \mathrm{C}$ ) encountered two regions of high ice concentrations. The first occurred between $\sim$ 19:58 and 20:01 UTC (corresponding to a distance of $11 \mathrm{~km}$; marker 4; contained 
Table 2. Details on periods when liquid water, but no ice were observed.

\begin{tabular}{|c|c|c|c|c|}
\hline $\begin{array}{l}\text { Flight and } \\
\text { section no. }\end{array}$ & Time & $\begin{array}{c}\text { Temp range } \\
\left({ }^{\circ} \mathrm{C}\right)\end{array}$ & $\begin{array}{c}\text { Mean } \\
\text { temp }\left({ }^{\circ} \mathrm{C}\right)\end{array}$ & $\begin{array}{c}\text { Mean/max/ } \\
\text { stddev LWC }\left(\mathrm{g} \mathrm{m}^{-3}\right)\end{array}$ \\
\hline \multicolumn{5}{|c|}{ Orographic/Lee wave cloud } \\
\hline 101-L1 & $12: 54: 57$ to $12: 56: 13$ & -2.8 to -5.4 & -4.2 & $0.10 / 0.12 / 0.01$ \\
\hline 102-L1 & $20: 23: 24$ to $20: 24: 28$ & -11.0 to -13.1 & -12.1 & $0.14 / 0.19 / 0.03$ \\
\hline 102-L2 & $20: 30: 13$ to $20: 31: 06$ & -10.1 to -11.3 & -10.5 & $0.13 / 0.21 / 0.04$ \\
\hline 102-L3 & $20: 34: 51$ to $20: 35: 44$ & -11.1 to -12.1 & -11.7 & $0.10 / 0.12 / 0.01$ \\
\hline 102-L4 & $20: 46: 23$ to $20: 47: 42$ & -11.2 to -12.5 & -11.8 & $0.15 / 0.18 / 0.03$ \\
\hline 102-L5 & $20: 50: 02$ to $20: 51: 03$ & -12.0 to -13.1 & -12.5 & $0.19 / 0.25 / 0.05$ \\
\hline 102-L6 & $21: 04: 19$ to $21: 05: 18$ & -10.2 to -11.3 & -10.9 & $0.15 / 0.18 / 0.03$ \\
\hline 104-L1 & $19: 25: 31$ to $19: 26: 16$ & -17.2 to -20.8 & -19.7 & $0.18 / 0.26 / 0.06$ \\
\hline 104-L2 & $21: 37: 45$ to $21: 38: 40$ & -19.1 to -20.0 & -19.6 & $0.30 / 0.41 / 0.06$ \\
\hline 104-L3 & $21: 55: 18$ to $21: 56: 20$ & -20.0 to -21.1 & -20.7 & $0.23 / 0.34 / 0.08$ \\
\hline \multicolumn{5}{|c|}{ Cloud layers over Larsen C } \\
\hline 99-L1 & $15: 37: 45$ to $15: 38: 47$ & -16.5 to -16.8 & -16.6 & $0.16 / 0.18 / 0.01$ \\
\hline 99-L2 & $15: 39: 59$ to $15: 40: 48$ & -16.1 to -16.4 & -16.2 & $0.13 / 0.14 / 0.00$ \\
\hline 99-L3 & $15: 45: 35$ to $15: 46: 40$ & -15.9 to -16.2 & -16.0 & $0.11 / 0.12 / 0.01$ \\
\hline 99-L4 & $15: 47: 12$ to $15: 47: 59$ & -15.9 to -16.3 & -16.1 & $0.13 / 0.15 / 0.01$ \\
\hline 99-L5 & $15: 48: 13$ to $15: 49: 41$ & -16.3 to -16.5 & -16.4 & $0.15 / 0.16 / 0.01$ \\
\hline 99-L6 & $15: 49: 43$ to $15: 50: 58$ & -16.2 to -16.5 & -16.3 & $0.15 / 0.16 / 0.01$ \\
\hline 99-L7 & $15: 52: 41$ to $15: 54: 08$ & -16.1 to -16.2 & -16.1 & $0.09 / 0.11 / 0.01$ \\
\hline \multicolumn{5}{|c|}{ Hallett Mossop Zone cloud } \\
\hline 99-L8 & $15: 02: 22$ to $15: 03: 29$ & -5.7 to -6.0 & -5.9 & $0.12 / 0.18 / 0.03$ \\
\hline 100-L1 & $13: 55: 59$ to $13: 56: 48$ & -5.9 to -6.8 & -6.4 & $0.17 / 0.23 / 0.05$ \\
\hline 100-L2 & $14: 27: 17$ to $14: 28: 02$ & -3.9 to -4.2 & -4.1 & $0.17 / 0.27 / 0.06$ \\
\hline 100-L3 & $14: 40: 58$ to $14: 42: 17$ & -4.8 to -6.7 & -6.3 & $0.25 / 0.32 / 0.07$ \\
\hline 100-L4 & $14: 42: 25$ to $14: 44: 11$ & -5.8 to -6.1 & -5.9 & $0.24 / 0.28 / 0.01$ \\
\hline 100-L5 & $14: 46: 45$ to $14: 47: 58$ & -5.9 to -6.1 & -6.0 & $0.21 / 0.25 / 0.02$ \\
\hline 104-L4 & $19: 53: 48$ to $19: 56: 10$ & -3.9 to -5.9 & -5.0 & $0.13 / 0.17 / 0.02$ \\
\hline 104-L5 & $20: 02: 57$ to $20: 04: 17$ & -2.4 to -2.6 & -2.5 & $0.18 / 0.29 / 0.07$ \\
\hline 104-L6 & $20: 04: 42$ to $20: 05: 33$ & -2.2 to -2.5 & -2.3 & $0.20 / 0.25 / 0.03$ \\
\hline 104-L7 & $20: 17: 24$ to $20: 19: 09$ & -5.0 to -5.3 & -5.2 & $0.13 / 0.19 / 0.03$ \\
\hline
\end{tabular}

within period 104-i5 in Table 1) and the second between $\sim$ 20:06 to 20:09 UTC, (covering $10.15 \mathrm{~km}$; marker 5; contained within period 104-i6). Ice concentrations were orders of magnitude larger than previously observed at colder temperatures. Maximum $5 \mathrm{~s}$ concentrations in these two regions were $0.73 \pm 0.171^{-1}$ (Fig. 8a) and 6.6 $\pm 0.51^{-1}$ (Fig. 8b), respectively, (at $T=-2{ }^{\circ} \mathrm{C}$ ). Maximum $60 \mathrm{~s}$ values were $0.37 \pm 0.031^{-1}$ and $2.7 \pm 0.11^{-1}$.

The HM secondary ice multiplication process (SIP) due to splinter ejection during riming of ice crystals is known to occur between temperatures of -3 to $-8^{\circ} \mathrm{C}$, being most effective at $-5^{\circ} \mathrm{C}$. Thus the high ice concentrations observed here were likely to have been initiated by HM SIP slightly higher in altitude than the sampled layer and transported down to the aircraft observation level, which averaged $-2{ }^{\circ} \mathrm{C}$ (range -1.9 to $\left.2.6^{\circ} \mathrm{C}\right)$.
Figure 9 shows examples of CIP images recorded within the two high ice concentration HM regions described above. In the first region of lower ice concentrations (corresponding to Fig. 8a) the images (Fig. 9a) were dominated by super cooled droplets with LWC contents of up to $0.26 \mathrm{~g} \mathrm{~m}^{-3}$. The relatively few ice crystals present had maximum dimensions between $138-238 \mu \mathrm{m}$ some of which were readily identifiable as ice columns and some were rimed. It is possible that the aircraft was sampling either below a region of weak HM production or at the edge of a stronger HM region.

Figure 9b shows the CIP images for the higher concentration region. The images are overwhelmed by columns, many of them rimed, covering a large range of sizes, with some $>1.4 \mathrm{~mm}$ in length. The ratio of ice crystals to droplets was also much larger and the LWC significantly lower $\left(<0.05 \mathrm{~g} \mathrm{~m}^{-3}\right)$. A significant number of aggregates of large columns are also seen, which makes it more likely that they 
(a)

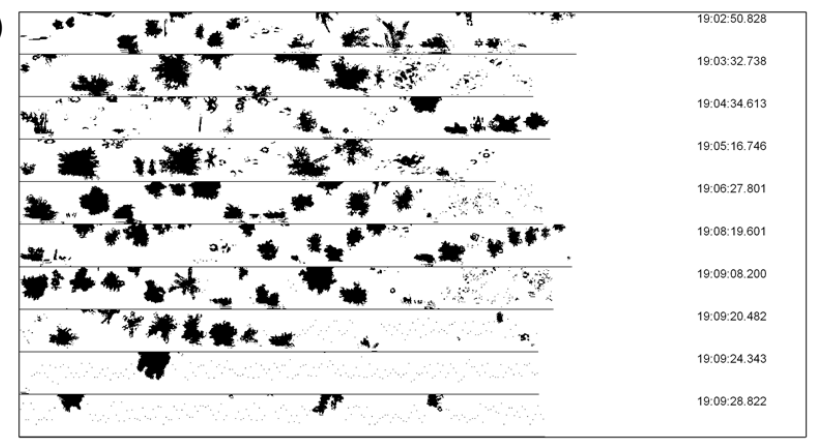

(b)

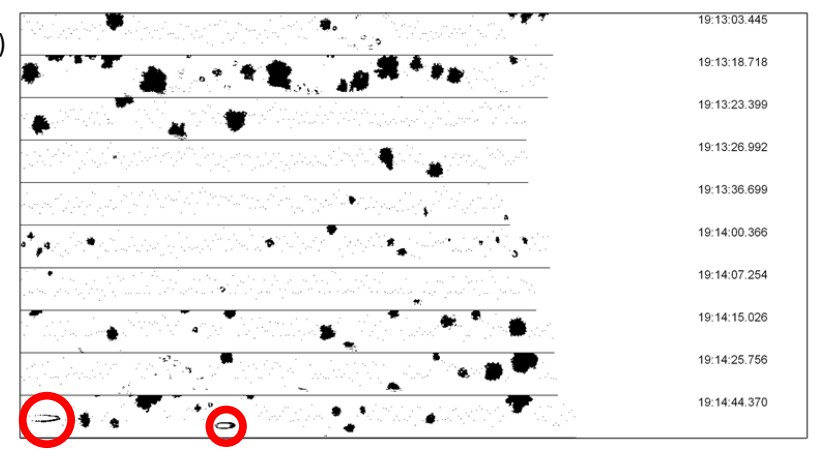

(c)

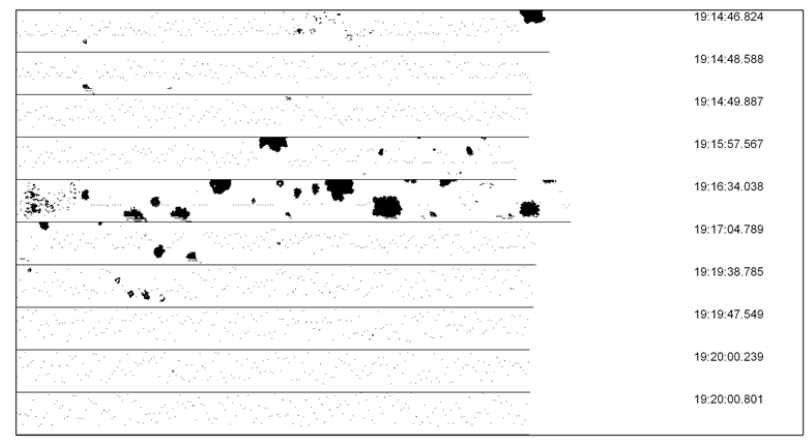

Fig. 6. (a-c) 2-D CIP images recorded on flight \#104 between 19:02:50 to 19:20:00 during the ascent through orographic cloud over the Antarctic Peninsula. The timestamps correspond to the images at the righthand side of each strip. These are the raw images, before ice shattering artefacts have been removed. The particles highlighted with red circles are speculated to be raindrops.

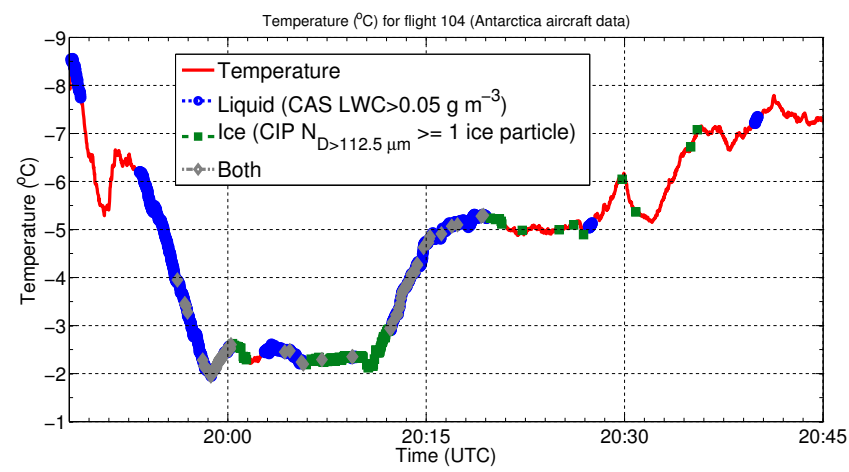

Fig. 7. As for Fig. 5a except for the period of the descent through the Hallett Mossop (HM) zone, the straight and level run at $-2{ }^{\circ} \mathrm{C}$ and the ascent to above the HM zone. (a)

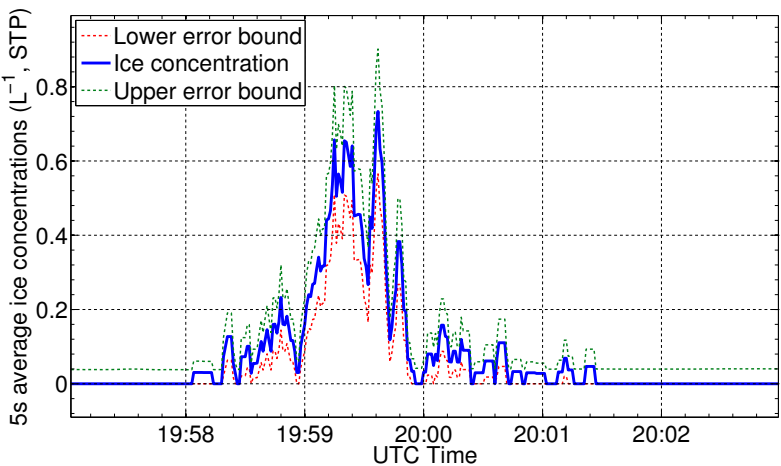

(b)

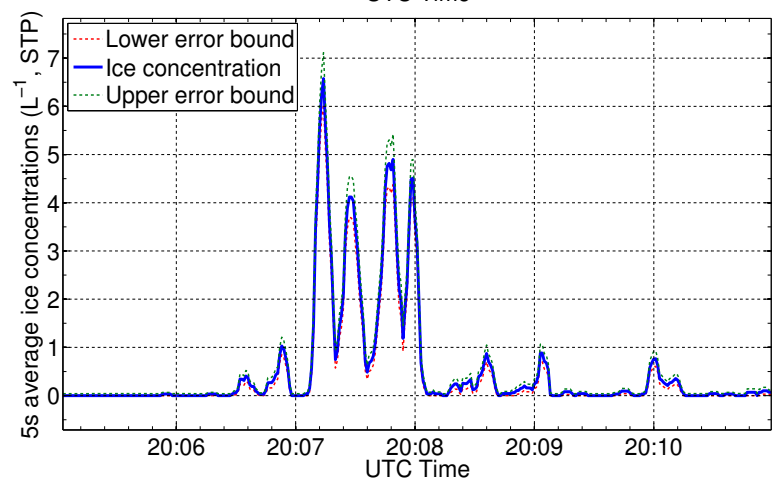

Fig. 8. As for Fig. 5c except for: (a) - the lower ice concentration Hallett Mossop period; (b) - the higher concentration Hallett Mossop zone period. See text for details. Also, the averages here are over the shorter period of $5 \mathrm{~s}$.

will have sedimented from higher in the cloud again supporting the argument that the aircraft was sampling just below an area of HM SIP.

In between the two ice regions mentioned above were a couple of ice-free regions (periods 104-L5 and 104-L6) containing excursions in LWC of up to $\sim 0.29 \mathrm{~g} \mathrm{~m}^{-3}$. During the initial descent through the HM temperature region no ice was detected, although there was significant supercooled water (period 104-L4 in Table 2). Similarly very little ice was detected on the subsequent ascent (period 104-L7) out of the region. However, during the ascent and descent periods the aircraft only very briefly transited the HM temperature zone. The results suggest that active HM regions were confined to favoured pockets.

One possible explanation for a lack of HM process in certain regions comes from laboratory studies (Mossop, 1985; Saunders and Hosseini, 2001), which showed that the HM process critically requires the presence of droplets with diameters $<12 \mu \mathrm{m}$ and $>25 \mu \mathrm{m}$ in order to become active. The CAPS CAS instrument measured droplet size distributions in the supercooled liquid cloud region during the descent (to $-2{ }^{\circ} \mathrm{C}$ ) and revealed that at $-5{ }^{\circ} \mathrm{C}$, where the $\mathrm{HM}$ process has been shown to be the most active, small droplets $(<12.5 \mu \mathrm{m})$ comprised $\sim 80 \%$ of the total droplet concentration, whereas droplets $>25 \mu \mathrm{m}$ represented $\sim 2 \%$ 
(a)

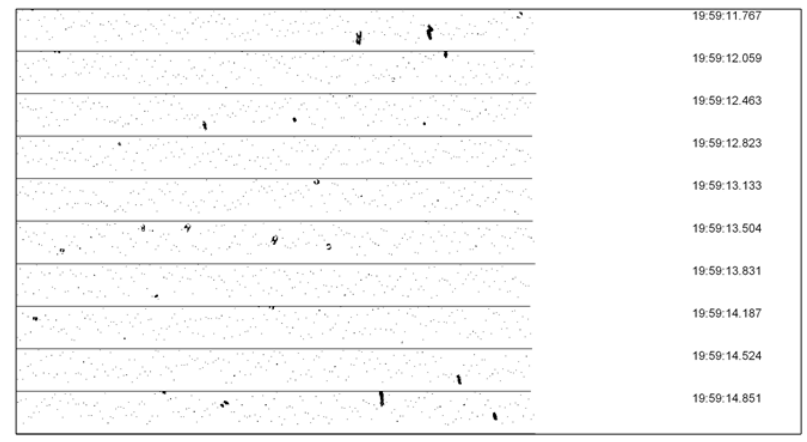

(b)

\begin{tabular}{|c|c|}
\hline 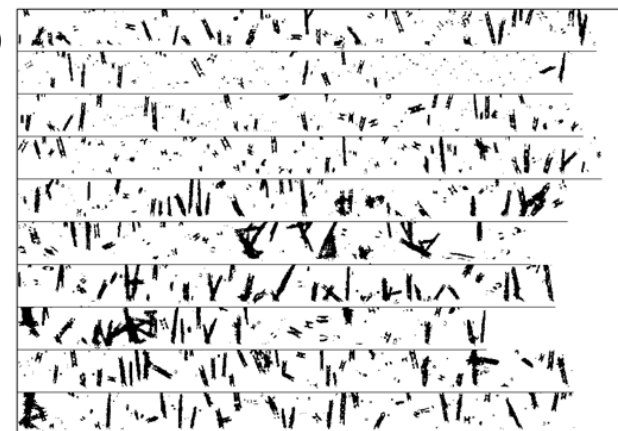 & 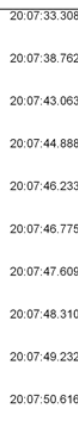 \\
\hline
\end{tabular}

Fig. 9. 2-D CIP image examples taken during the active Hallett Mossop period of flight \#104. (a) - for the low ice concentration period, 19:59:11 to 19:59:15, $\left(T=-2{ }^{\circ} \mathrm{C}\right)$; (b) - for the high ice concentration period, 20:07:33 to 20:07:50, $\left(T=-2^{\circ} \mathrm{C}\right)$. The timestamps are as in Fig. 6.

of the population. Mossop (1985) gives estimates of the number of ice crystals produced in the HM process for every large droplet that is frozen. This number varied between $\sim 1 \times 10^{-3}$ and $12 \times 10^{-3}$ and was found to be mainly dependent (although not monotonically) on the accretion velocity between the water and ice hydrometeors. The maximum concentration of large droplets observed in the descent was $\sim 4 \mathrm{~cm}^{-3}$, which, if they all were to freeze, would give a splinter concentration of between 4 and $481^{-1}$. This likely represents an upper limit to this range since all of the large droplets may not freeze in reality. The lower end of this range agrees with the maximum ice concentrations seen in the precipitating region below and suggests that the number of large droplets would likely have been enough to allow the HM process to produce significant concentrations of ice once droplet freezing was initiated. Mossop (1985) also suggests that the $\mathrm{HM}$ process is most efficient when the ratio of small to large droplets is high, as in this case.

The most plausible remaining explanation for the lack of observed ice during the profiles then becomes a lack of primary ice particles due to a deficiency of IN. Ice particles are needed to initiate the riming process, which is fundamental to the HM mechanism. At HM zone temperatures, typical IN concentrations are predicted to be extremely low, although it has been speculated that there are some IN (mainly bacteria) that can nucleate ice at temperatures as warm as $-2^{\circ} \mathrm{C}$ (see
Möhler et al., 2007; Hoose et al., 2010). However, it is more likely that the ice particles required to initate the HM process will come through precipitation or advection from lower temperature (typically $<-12^{\circ} \mathrm{C}$ ) heterogeneous primary ice formation regions aloft. In low aerosol environments such as these, this process is likely to be spatially highly variable and this would then be reflected in subsequent variability in the provision of rimers for the HM and SIP mechanisms at lower levels. This is consistent with the large variability and very low concentrations of ice observed higher in the cloud at lower temperatures (as described above), and was a general feature in the other Antarctic clouds sampled (discussed shortly).

These observations coupled with the prevalence of extensive low-level stratus over the Antarctic Larsen C Ice Shelf highlight the potential importance, of the HM process for generating significant concentrations of ice particles within this low IN region, but also demonstrates the somewhat chaotic and inhomogeneous nature of this process.

\subsection{Summary of the other flights}

\subsubsection{Flight 99}

Orographic cloud associated with northwesterly flow was observed above the western slope of the AP. This was upwind of the AP ridge, but downwind of Adelaide Island. Ice was detected in a layer between 1.5 and $2.25 \mathrm{~km}$ in altitude (encompassing periods $99-\mathrm{i} 2$ and $99-\mathrm{i} 3$ in Table 1) with a maximum $60 \mathrm{~s}$ concentration of $0.04 \pm 0.011^{-1}$ observed at $T=-14.2^{\circ} \mathrm{C}$. No liquid water was detected in this cloud (RH w.r.t. liquid was $\sim 70-80 \%$ ). It is possible that there was a liquid water containing cloud above and that the ice was precipitation from this, which would be consistent with the relatively large size of the ice (mode size of $350 \mu \mathrm{m}$, but with an upper size limit of $\sim 1000 \mu \mathrm{m})$. This is supported by MODIS cloud top temperature and cloud phase information from 14:15 and 18:15 UTC (1.5 h before and after the period in question, respectively; not shown), which revealed the presence of bands of mixed phase cloud caused by lee waves forced by the northwesterly flow over Adelaide Island and the AP. This cloud was at temperatures similar to those sampled by the aircraft according to the earlier satellite image, but around 5-7 K cooler according to the later image.

Earlier, whilst over the Larsen C Ice Shelf, the aircraft sampled a layer of cloud between 1.6 and $1.95 \mathrm{~km}(T=-15$ to $-16.5^{\circ} \mathrm{C}$ ) below a strong temperature inversion in which peak LWC values of $0.19 \mathrm{~g} \mathrm{~m}^{-3}$ were recorded at $1.8 \mathrm{~km}$ (contained in period 99-i5). Ice concentrations were very low reaching a $60 \mathrm{~s}$ maximum of $0.020 \pm 0.007 \mathrm{1}^{-1}$. In fact, several periods within 99-i5 met the LWC only criteria for Table 2 (99-L1 through 99-L7). Ice precipitation (period 99-i4) was observed up to $0.75 \mathrm{~km}$ below this layer in which concentrations were similar to those in the cloud. 
Below this a further cloud layer was sampled between 0.36 and $0.44 \mathrm{~km}\left(T=-6.3\right.$ to $-5.5^{\circ} \mathrm{C}$, encompassing period 99-L8). This layer extended up from the surface to $\sim 0.5 \mathrm{~km}$. The temperature at the penetration level corresponded to the optimum expected for the HM process to be active. LWC was encountered with values up to $0.18 \mathrm{~g} \mathrm{~m}^{-3}$, but no ice was observed. The precipitating ice mentioned above was sampled less than $8 \mathrm{~km}$ from the nearest edge of the sample run in this layer. However, it is likely that this ice evaporated before reaching the layer since the relative humidity w.r.t. ice reached as low as $60 \%$ in the air above. Besides this, the number of large droplets $(D>25 \mu \mathrm{m})$ was much smaller in this case $\left(\sim 0.025 \mathrm{~cm}^{-3}\right)$, which using the method described in Sect. 3.1.3 would give maximum ice concentrations in the range of only $0.025-0.31^{-1}$. Whilst likely detectable, such ice concentrations are low compared to those seen in the HM regions of flight 104 and might suggest that a lack of large droplets also played a role in suppressing the HM process in this area.

\subsubsection{Flight 100}

On this day the aircraft flew through some stratocumulus cloud to the northwest of Rothera, making repeated level measurement runs over a distance of $\sim 70 \mathrm{~km}$. Temperatures ranged from -0.5 to $-7^{\circ} \mathrm{C}$ up to altitudes of $\sim 1.1 \mathrm{~km}$.

An ice-only region on the lowest flight leg (period 100i1; $0.15-0.2 \mathrm{~km}$ in altitude; maximum $60 \mathrm{~s}$ concentration of $1.28 \pm 0.061^{-1}$ ) was likely to have been the result of precipitation from a HM region above since the CIP revealed the presence of large columns that were often aggregated. The highest concentrations from this flight were observed between temperatures of -4.2 and $-6^{\circ} \mathrm{C}$ with a maximum $60 \mathrm{~s}$ concentration of $6.26 \pm 0.151^{-1}$ recorded at the $-4.3^{\circ} \mathrm{C}$ temperature level (period 100-i3). This corresponds well with the expected region of maximum secondary ice production by the HM mechanism and the detected ice columns are characteristic of this process. In this temperature range the number of large droplets $(D>25 \mu \mathrm{m})$ was $\sim 0.9 \mathrm{~cm}^{-3}$. Using the method described in Sect. 3.1.3 this would allow maximum HM ice concentrations in the range of $0.9-10.81^{-1}$, which is comparable with the maximum ice concentrations actually observed.

Given the low concentrations of primary ice particles observed in the flights presented in this manuscript it might seem unlikely that in-cloud nucleation would be sufficient to initiate the HM process given that the cloud top temperature of the sampled cloud was only around $-7^{\circ} \mathrm{C}$. However, a MODIS satellite image from 14:05 UTC (not shown) reveals that around the time at which the HM region was sampled higher altitude cloud with top temperatures of $\sim-35$ to $-40^{\circ} \mathrm{C}$ was present above the flight region. Thus, it is possible that this may have provided some ice seeding from above. However, it is unknown whether the relative humidity in the air between the clouds (estimated to be a layer around $3 \mathrm{~km}$ thick) was high enough to prevent ice evaporation.

Ice-free liquid-only regions were frequently present in the HM temperature zone during flight \#100 (see Table 2). The different liquid only regions in flight 100 sometimes had droplet spectra that likely contained enough large droplets to produce significant HM splinter concentrations and sometimes did not. This suggests that both droplet size dependence and a lack of primary ice may have been the cause of the lack of the HM process at different times. Again, this demonstrates the complicated nature of this process.

\subsubsection{Flight 101}

Cloud in north-easterly flow was observed on this flight on the downwind side of the AP crest, above the crest and also above the slope of the upwind side of the crest.

Above the mountain slopes, the maximum concentrations sampled were $0.22 \pm 0.031^{-1}$ (downwind slope; $T=$ $-10.8^{\circ} \mathrm{C}$; period $101-\mathrm{i} 1$ ) and $0.15 \pm 0.021^{-1}$ (upwind slope; $T=-12$ to $-13{ }^{\circ} \mathrm{C}$; contained within period $\left.101-\mathrm{i} 2\right)$. Later in the flight a similar region was observed just above the top of the downwind slope, but some way to the north of where the other cloud was observed. Encompassing period 101-i3 (at an altitude of $\sim 3250 \mathrm{~m}$ ) this region showed a maximum $60 \mathrm{~s}$ ice concentration of only $0.023 \pm 0.0081^{-1}$ at $-10.2^{\circ} \mathrm{C}$ with very little or no liquid water.

Above the slopes on both sides of the AP, the lack of LWC and the fact that the ice particles consisted mainly of large snowflake dendrites and irregular particles suggests that at least some of this ice was likely to have been precipitation from colder cloud above. MODIS cloud top temperatures (not shown) revealed the presence of cloud with a top at $-28^{\circ} \mathrm{C}$. However, ice was also sampled above the mountain ridge between 4.25 and $4.5 \mathrm{~km}$ in altitude where the aircraft flew for $35 \mathrm{~km}$ at a near constant temperature of $-19^{\circ} \mathrm{C}$. Ice was observed throughout this leg with concentrations varying from $0.035 \pm 0.011^{-1}$ up to a maximum of $0.12 \pm 0.021^{-1}$ (contained within period 101-i2). Some liquid water was observed in this region and the ice crystals spanned a range of sizes suggesting some local cloud formation, although some precipitation from above cannot be ruled out also. It is therefore likely that some of the ice observed above the slopes came from this warmer region of cloud formation at $-19^{\circ} \mathrm{C}$, as well as potentially from temperatures as cold as $-28^{\circ} \mathrm{C}$.

Generally the ice number concentrations within the precipitating regions were similar to those within the warmer LWC containing cloud.

\subsubsection{Flight 102}

For this flight the aircraft flew around the Marguerite Bay region on the west side of the AP in order to sample some lee wave clouds at around $3200 \mathrm{~m}$. A series of straight and level runs were made through the wave clouds near that altitude 
in a direction approximately parallel to that of the wind. A vertical wave amplitude of $1250 \mathrm{~m}$ was estimated by assuming a sinusoidal wave and using the observed mean horizontal wind-speed, maximum vertical wind speed and wavelength. As confirmed by the temperature and vertical velocity measurements, the aircraft cut through a series of peaks and troughs of waves that were likely stacked vertically on top of each other. If this was the case then the air at the peaks would have previously been up to $1250 \mathrm{~m}$ below the (approximately constant) sampling height and the air at the troughs up to $1250 \mathrm{~m}$ above.

The temperature varied between approximately -10 and $-13^{\circ} \mathrm{C}$ for most of the observed oscillations. Liquid only (LWC values of up to $0.25 \mathrm{~g} \mathrm{~m}^{-3}$, see Table 2) and mixed phase regions were mainly only present near the peaks of the sampled waves. Ice-only regions were frequently found at the troughs of the waves indicating that ice was surviving the downward parts of the waves and coming down from cloud above. Such air could have experienced temperatures up to around 10 degrees colder than the temperatures sampled, which would correspond to around -20 to $-22^{\circ} \mathrm{C}$. The likelihood of some ice having experienced sedimentation gives rise to the possibility that some of the ice observed was nucleated at even colder temperatures than this.

Outside of the regions identified as contaminated (see Sect. 2), ice was seen in four main periods (Table 1) with $60 \mathrm{~s}$ averages ranging between $0.03 \pm 0.01$ and $0.16 \pm 0.021^{-1}$.

\section{IN parameterization comparisons}

One of the aims of this study is to test the applicability of ice nuclei parameterizations (e.g. D10; Meyers et al., 1992; Fletcher, 1962; Cooper, 1986) for the Antarctic Peninsula region. The scheme of $D 10$ was novel because, unlike the other schemes just mentioned, it also incorporated aerosol concentrations (as well as temperature) as a parameter that controls IN concentrations. $D 10$ found that this allowed a much better fit to several IN concentration datasets than the older parameterizations that were based on temperature alone. However, it should also be noted that the datasets in $D 10$ contained only a few observations of IN concentrations $<0.11^{-1}$ and these were at temperatures of -23 to $-35^{\circ} \mathrm{C}$, which is slightly colder than the coldest temperatures sampled here. In fact for these points the parameterization predicted values that were somewhat high, which is consistent with our findings here (discussed shortly).

To make IN concentration predictions using the $D 10$ parameterization requires a concentration of aerosol particles with diameters greater than $0.5 \mu \mathrm{m}\left(N_{0.5}\right)$ since $D 10$ argues that IN particles are usually in this size range (residue measurements from ice particles nucleated in their diffusion chamber suggested a mode size of $0.5 \mu \mathrm{m}$ ). There are likely to be some IN that are smaller than this, but the choice of
$0.5 \mu \mathrm{m}$ is a compromise designed to minimize the contribution from accumulation mode aerosol.

One likely exception is in marine boundary layers where sea salt aerosol have been observed to contribute significantly to the total aerosol numbers for sizes $>0.5 \mu \mathrm{m}$ (O'Dowd et al., 1997). Sea salt has little or no ice nucleation ability (D10) and so its presence would be likely to disrupt the correlation between total aerosol and IN concentrations. All of the cloud in the "orographic" and "cloud layers over Larsen C" categories were demonstrably above the boundary layer with the exception of clouds in the latter category in Flight 99. Sea salt is usually quickly removed because of its efficiency as $\mathrm{CCN}$ and so it is likely that the aerosols measured in these clouds contained little of it. The clouds in Flight 99 were above the ice shelf surface and thus also were unlikely to be contaminated by sea salt considering its short atmospheric lifetime. The HM flights were closer to the surface and thus were more likely affected (especially flight 100, which was over open ocean). However, these types of clouds were generally not used to characterize heterogeneous ice nucleation.

Aerosol concentrations in this paper are estimated using the CAS instrument when it could be ascertained that the aircraft was out of cloud. They were binned by RH and averages were taken at as low an RH as possible to try and minimize swelling effects of smaller aerosols to sizes $>0.5 \mu \mathrm{m}$. The aerosol concentrations taken as close as possible to each icecontaining flight segment are listed in Table 3 along with the highest RH value included in the average. For some flight segments the RH was always quite high making aerosol estimates difficult and making it likely that overestimation may have occurred.

The CAS instrument has a lower size limit of $0.62 \mu \mathrm{m}$ and thus we use the aerosol concentration above this size as a surrogate for the $N_{0.5}$ parameter required for $D 10$. This would tend towards the underestimation of $N_{0.5}$. Also, in $D 10$ there was a maximum possible sampled aerosol size of $1.6 \mu \mathrm{m}$. Here we impose an upper limit of $2 \mu \mathrm{m}$ for approximate consistency with this. An exact match is not possible given the channels available from the CAS instrument. Thus, along with the uncertainty associated with high RH and the inherent instrument uncertainty, the precise measurement of $N_{0.5}$ is difficult. However, we will demonstrate shortly that the $D 10$ parameterization is not especially sensitive to its exact value in the parameter space in question here.

Figure 10 shows the concentrations of IN predicted by the $D 10$ parameterization using aerosol values of $0.1 \mathrm{~cm}^{-3}$ and $0.4 \mathrm{~cm}^{-3}$ (which approximately covers the range of the aerosol concentrations measured for the considered cloud legs) along with those predicted by three other popular parameterizations. The Cooper (1986) scheme was widely used in version 3 of the WRF model as part of the Morrison et al. (2009) microphysics package, which was probably the most sophisticated of the packages available. The Meyers et al. (1992) parameterization was widely used in the RAMS 
Table 3. Predicted IN values from various parameterizations (see text) at the temperature of the observed maximum ice concentrations for the periods identified in Table 1. Also shown are aerosol concentrations observed near to these sections along with the maximum relative humidity value at which aerosol averages were taken.

\begin{tabular}{|c|c|c|c|c|c|c|c|c|c|}
\hline \multirow{2}{*}{$\begin{array}{l}\text { Flight and } \\
\text { section no. }\end{array}$} & \multirow{2}{*}{$\begin{array}{c}\text { Mean ice conc } \\
\left(1^{-1}\right)\end{array}$} & \multirow{2}{*}{$\begin{array}{c}\text { Max/stddev } \\
60 \text { s ice conc }\left(1^{-1}\right)\end{array}$} & \multirow{2}{*}{$\begin{array}{c}\text { Temp of } \\
\max \text { conc } \\
\left({ }^{\circ} \mathrm{C}\right)\end{array}$} & \multirow{2}{*}{$\begin{array}{c}\text { Max RH } \\
\text { for aerosol } \\
(\%)\end{array}$} & \multirow{2}{*}{$\begin{array}{c}\text { Observed } \\
\text { aerosol conc. } \\
\quad\left(\mathrm{cm}^{-3}\right)\end{array}$} & \multicolumn{3}{|c|}{ Predicted IN value $\left(1^{-1}\right)$} & \multirow[b]{2}{*}{ Fletcher } \\
\hline & & & & & & DeMott & Cooper & Meyers & \\
\hline \multicolumn{10}{|c|}{ Orographic/Lee wave cloud } \\
\hline 99-i1 & $0.011 \pm 0.004$ & $0.014 \pm 0.006 / 0.002$ & -14.5 & 50 & $0.33 \pm 0.05$ & 0.29 & 0.41 & 3.9 & 0.06 \\
\hline $99-\mathrm{i} 2$ & $0.007 \pm 0.002$ & $0.015 \pm 0.005 / 0.004$ & -14.4 & 50 & $0.33 \pm 0.05$ & 0.28 & 0.4 & 3.8 & 0.057 \\
\hline $101-\mathrm{i} 2$ & $0.073 \pm 0.003$ & $0.15 \pm 0.02 / 0.035$ & -12.4 & 70 & $0.15 \pm 0.02$ & 0.14 & 0.22 & 2.9 & 0.017 \\
\hline $101-\mathrm{i} 3$ & $0.011 \pm 0.002$ & $0.023 \pm 0.008 / 0.007$ & -10.2 & $70^{*}$ & $0.15 \pm 0.02 *$ & 0.081 & 0.11 & 2.1 & 0.005 \\
\hline 102-i1 & $0.019 \pm 0.003$ & $0.037 \pm 0.009 / 0.008$ & -9.8 & 75 & $0.19 \pm 0.03$ & 0.077 & 0.098 & 2.0 & 0.004 \\
\hline $102-\mathrm{i} 2$ & $0.032 \pm 0.003$ & $0.16 \pm 0.02 / 0.044$ & -10.8 & 75 & $0.19 \pm 0.03$ & 0.1 & 0.13 & 2.3 & 0.007 \\
\hline $102-\mathrm{i} 3$ & $0.013 \pm 0.003$ & $0.030 \pm 0.008 / 0.010$ & -10.2 & 75 & $0.19 \pm 0.03$ & 0.087 & 0.11 & 2.1 & 0.005 \\
\hline $102-\mathrm{i} 4$ & $0.013 \pm 0.002$ & $0.059 \pm 0.012 / 0.015$ & -11.6 & 75 & $0.19 \pm 0.03$ & 0.12 & 0.17 & 2.5 & 0.011 \\
\hline 99-i4 & $0.007 \pm 0.002$ & $0.017 \pm 0.007 / 0.005$ & -13.8 & 50 & $0.33 \pm 0.05$ & 0.25 & 0.33 & 3.5 & 0.039 \\
\hline 99-i5 & $0.007 \pm 0.001$ & $0.020 \pm 0.007 / 0.004$ & -16.5 & 50 & $0.33 \pm 0.05$ & 0.41 & 0.75 & 5.2 & 0.2 \\
\hline $104-\mathrm{i} 3$ & $0.008 \pm 0.002$ & $0.012 \pm 0.005 / 0.003$ & -17.7 & 40 & $0.15 \pm 0.03$ & 0.35 & 1.1 & 6.2 & 0.41 \\
\hline $104-\mathrm{i} 4$ & $0.011 \pm 0.002$ & $0.032 \pm 0.010 / 0.007$ & -13.4 & 60 & $0.15 \pm 0.03$ & 0.17 & 0.29 & 3.3 & 0.031 \\
\hline \multicolumn{10}{|c|}{ Hallett Mossop Zone ice } \\
\hline 100-i1 & $0.52 \pm 0.02$ & $1.28 \pm 0.06 / 0.38$ & -0.7 & 75 & $0.42 \pm 0.05$ & $1.9 \times 10^{-5}$ & 0.006 & 0.59 & $1.5 \times 10^{-5}$ \\
\hline $100-\mathrm{i} 2$ & $1.14 \pm 0.02$ & $3.44 \pm 0.11 / 1.01$ & -2.3 & 75 & $0.42 \pm 0.05$ & $9.1 \times 10^{-4}$ & 0.01 & 0.72 & $4 \times 10^{-5}$ \\
\hline $100-\mathrm{i} 3$ & $1.47 \pm 0.02$ & $6.26 \pm 0.15 / 1.78$ & -4.3 & 75 & $0.42 \pm 0.05$ & 0.007 & 0.018 & 0.94 & $1.3 \times 10^{-4}$ \\
\hline $100-\mathrm{i} 4$ & $0.90 \pm 0.02$ & $4.77 \pm 0.12 / 1.28$ & -5.9 & 75 & $0.42 \pm 0.05$ & 0.019 & 0.03 & 1.2 & $3.4 \times 10^{-4}$ \\
\hline $100-\mathrm{i} 5$ & $0.05 \pm 0.01$ & $0.06 \pm 0.01 / 0.01$ & -5.6 & 75 & $0.42 \pm 0.05$ & 0.016 & 0.027 & 1.1 & $2.9 \times 10^{-4}$ \\
\hline
\end{tabular}

* The CAS probe inlet was iced up for the second part of the flight making aerosol measurements uncertain. The value from the earlier part of the flight in a similar region (section 101-i1) has been used.

model and was designed to represent IN resulting from both condensation and deposition processes. Here, and throughout this paper, water saturation conditions are assumed for the calculation of the supersaturation w.r.t. ice (an input requirement for the Meyers et al., 1992, scheme), which would be expected in the presence of liquid water.

The figure reveals that changes in $N_{0.5}$ by a factor of four produce only a limited change in the IN concentrations predicted by the $D 10$ scheme, especially at warmer temperatures. From the figure it is also evident that there is a very wide range of predicted IN concentrations between the different schemes with all schemes predicting higher numbers than the $D 10$ parameterization at temperatures colder than -17 to $-18^{\circ} \mathrm{C}$. This probably reflects the fact that most schemes are based on mid-latitude measurements and do not take into account the cleanliness of the air in more remote regions. The Meyers scheme gives by far the highest concentrations for the temperatures shown.

The values that would be predicted for the different IN parameterizations for the conditions of the different flight segments are shown in Table 3. The temperature at which the maximum ice concentration was observed was used, which would be likely to produce an underestimate in many cases since the observed ice is likely to have fallen (or advected in the case of the lee wave clouds) from colder temperatures at higher altitude.

All the schemes except for $D 10$ have a tendency to predict IN concentrations that are much higher than the observed maximum ice concentrations at colder temperatures. At warmer temperatures (but outside of the HM region) both the $D 10$ and Cooper schemes give similar numbers, which are fairly close to the observed maximum ice concentrations. 


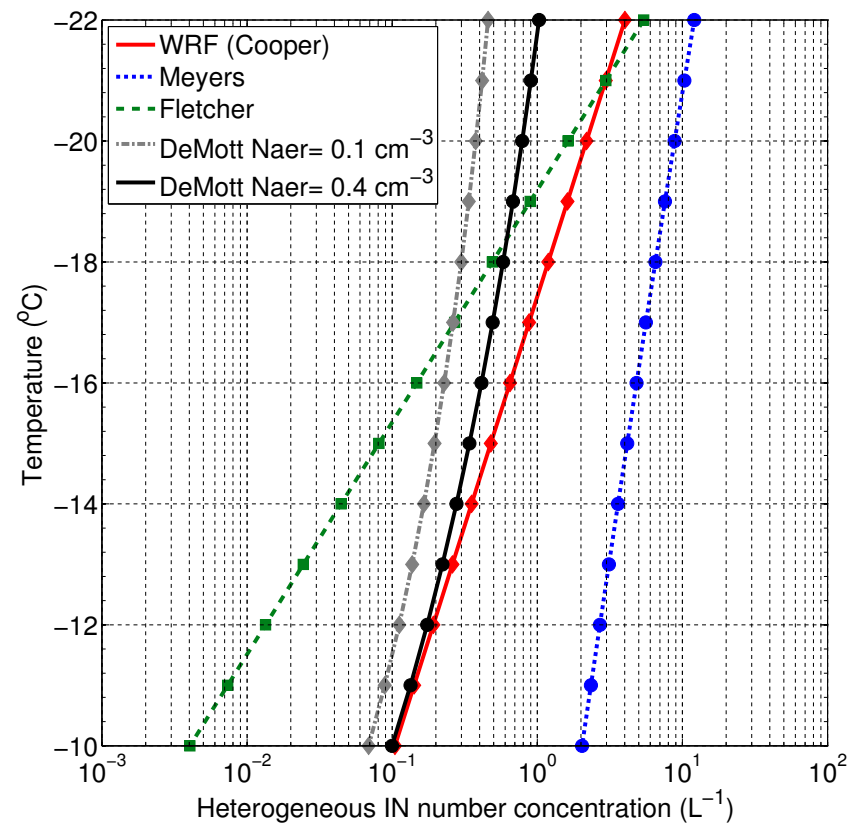

Fig. 10. IN concentrations predicted by various parameterizations as a function of temperature. Two different aerosol concentrations were used in the DeMott scheme as indicated in the legend. For the Meyers scheme water saturation conditions have been assumed to emulate condensation nucleation.

The Fletcher scheme tends to give numbers that are too low at warmer temperatures. Again, the Meyers scheme gives numbers that are much higher than the observed ice concentrations at all temperatures.

By contrast, in the HM temperature region all of the schemes except for Meyers predict IN concentrations that are much lower than the observed ice concentrations (both $60 \mathrm{~s}$ maximum values and flight segment averages), highlighting the importance of the ice multiplication process. Since the Meyers IN predictions are far too high at colder temperatures the agreement with the ice concentrations in the HM zone is almost certainly fortuitous.

Overall the $D 10 \mathrm{IN}$ scheme predicts numbers that are the most similar to those observed throughout the heterogeneous ice nucleating temperature range sampled. Figure 11 shows the predicted $D 10$ IN concentration vs. the observed maximum $60 \mathrm{~s}$ ice concentration during each flight segment. In order to try and take into account the uncertainties in the aerosol measurements discussed above, the $D 10$ values were also calculated using the observed aerosol concentrations both decreased and increased by a factor of 2 . This range is represented by the horizontal error bars. Even with these uncertainties taken into account, many of the points lie to the right of the one-to-one line indicating overprediction of IN by the $D 10$ scheme. This is despite using temperatures that were likely warmer than those at which the ice was nucleated (because of ice sedimentation and downward transportation in lee waves). However, three of the points lay just to the left of the line and several of them were fairly close to it, so that overall the comparison was reasonable. Again, the contrast of the high ice concentrations of the HM zone ice is evident.

\section{Discussion and conclusions}

This paper has presented aircraft measurements of in-cloud ice concentrations in Antarctica for the first time. Clouds were sampled on both sides of the Antarctic Peninsula over the ocean to the west and over the Larsen C Ice Shelf to the east, as well as over the slopes and above the mountain ridge. Cloud types included decoupled cloud layers associated with old fronts, deep clouds caused by active fronts, orographic cloud, lee wave cloud and stratocumulus. Several regions have been identified as those where only heterogeneous ice nucleation was likely to have been operating. The measurements in these cases were above the atmospheric boundary layer where contributions from wind driven suspension sources of surface ice and sea salt were likely to be insignificant. In those regions ice number concentrations were generally very low as summarised in Table 1 . Maximum $60 \mathrm{~s}$ ice concentrations ranged between 0.01 and $0.221^{-1}$.

The measured maximum ice concentrations were compared to the numbers predicted by various IN parameterizations. At heterogeneous ice formation temperatures the DeMott et al. (2010, D10) parameterization compared the most favourably. The other schemes generally predicted IN concentrations far higher than those observed, especially at colder temperatures. The D10 scheme uses aerosol concentrations as an input and so can take into account the cleanliness of the air, which would be likely to denote low IN concentrations. There are some fairly large uncertainties in the aerosol concentration measurements for these flights (see Sect. 4), but the $D 10$ parameterization is not very sensitive to concentration changes of a factor of 2 or so for the conditions in these clouds.

In many of the cases even the $D 10$ predictions were somewhat higher than the observed maximum ice concentrations, reflecting the likelihood that IN concentrations in this remote region are fairly low compared to regions with higher aerosol concentrations. However, since the approach used here was to compare predictions from IN parameterisations to the maximum ice concentrations observed (rather than the average), it is necessary to consider whether this approach is fair and to explore the issues associated with it.

First of all, IN concentrations are likely to vary spatially and temporally with resulting variations in nucleated ice concentrations. IN parameterization schemes are generally based on IN concentrations averaged from many samples and so, for a given temperature, are representative of average concentrations over a large volume. Thus it might be expected that the maximum ice concentrations in heterogeneous ice forming regions would be larger than those predicted by IN parameterizations. The reasonable match found between 

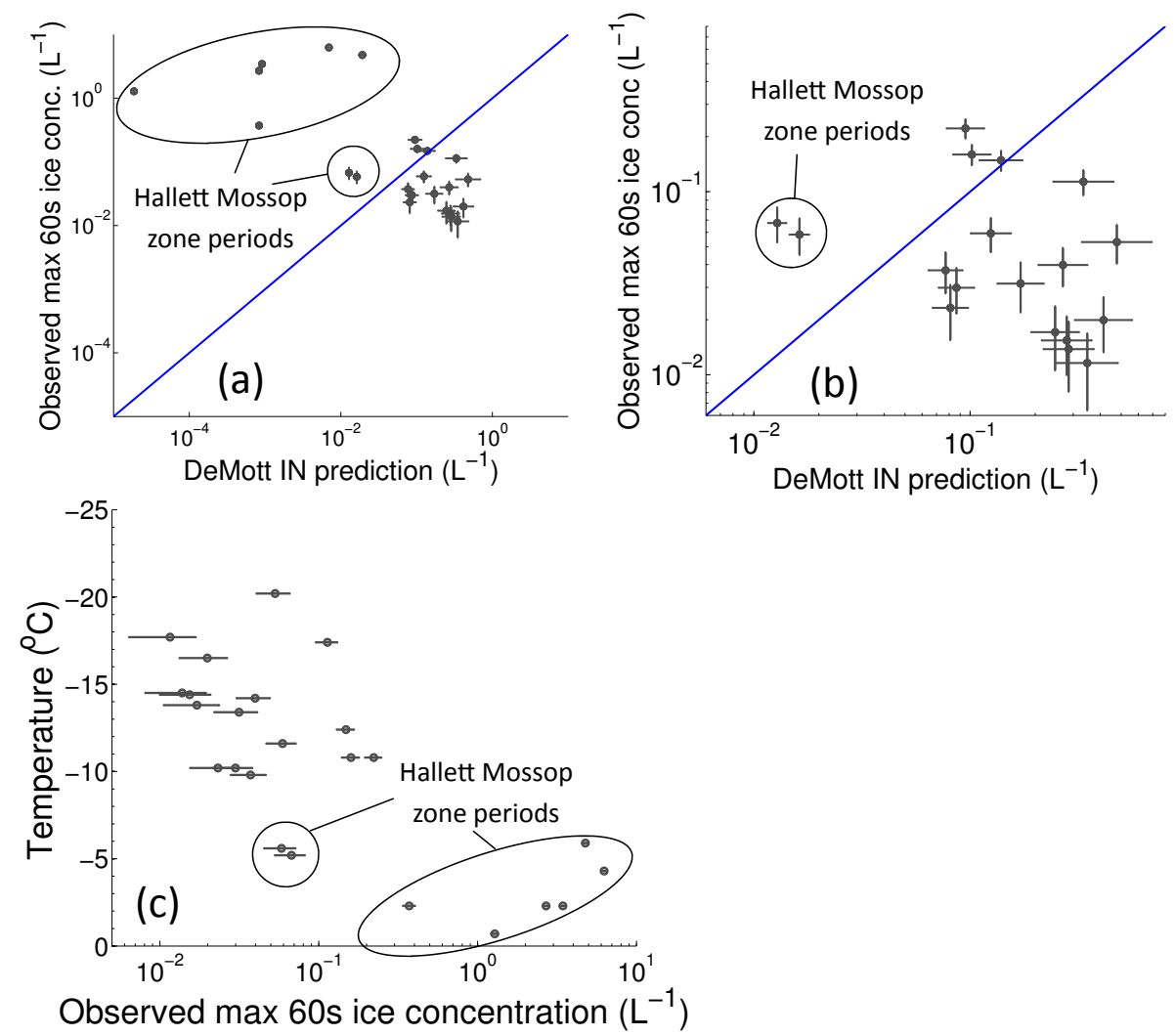

Fig. 11. (a and b) - Observed maximum $60 \mathrm{~s}$ ice concentrations from the different periods listed in Table 1 plotted against the IN concentration predicted by the DeMott et al. (2010) parameterization. The vertical error bars represent the standard Poisson uncertainty in the measured ice concentrations, whilst the left and right-hand sides of the horizontal error bars represent the IN values obtained if, respectively, half and double the observed aerosol concentrations are used in the parameterization. See the text for more details. (a) shows the points for all of the ice flight segments and (b) is in close up around the points from the heterogeneous ice nucleation regions. (c) shows the observed maximum $60 \mathrm{~s}$ ice concentrations (with Poisson errors) plotted against the observation temperature. Periods located in the Hallett Mossop ice multiplication regions are indicated.

maximum ice concentrations and $D 10$ predictions in this study might then suggest that the $D 10$ predictions were too high for this region.

However, it is also likely that precipitation and aggregation losses of ice after nucleation will reduce ice concentrations relative to IN concentrations. Ice detection is also hampered by the minimum size of ice crystals required for detection (in this study $D=112.5 \mu \mathrm{m}$ ). As discussed in Sect. 2.1 this is only likely to lead to underestimates of ice concentrations within $\sim 90 \mathrm{~m}$ of cloud top. It seems reasonable to assume that it would often be possible to sample ice crystals shortly after nucleation (but after enough time for growth to detectable sizes) in air parcels that have not experienced significant aggregation and precipitation depletion. In this case the maximum ice concentrations observed in heterogeneous IN regions might be those that best reflect IN concentrations, rather than mean ice concentrations. Since the ice concentrations observed were generally lower than predicted, the use of maximum values also gives a more conservative comparison.
In one case (flight 102) ice was observed in the downward phase of a lee wave at a temperature of $-11^{\circ} \mathrm{C}$ suggesting that the ice likely nucleated higher up at temperatures estimated to be as cold as $\sim-20$ to $-22{ }^{\circ} \mathrm{C}$. Additionally, in this and other cases the observed ice may have included precipitation from higher in altitude and thus colder temperatures. This would tend to produce a $D 10 \mathrm{IN}$ prediction that is too low, although the temperature dependence of the $D 10$ scheme is only modest.

How much weighting should be applied to the different competing effects discussed above is unknown. However, given the uncertainties, the matching with $D 10$ in at least some of the cases leads to the conclusion that the $D 10$ scheme does a reasonable job of predicting IN in this region, especially relative to the other IN schemes looked at.

These difficulties highlight the need in Antarctica for accurate measurements of IN and aerosol concentration data alongside in-situ cloud microphysical and thermodynamic data to allow a more accurate assessment of cloud parameterizations. Such data would also allow detailed cloud and 
microphysical modelling, which may give answers to some of the problems just mentioned (i.e. determining the details of the processes that likely occurred to produce the sampled ice).

The observed ice concentrations did not seem to show a strong dependence on temperature (Fig. 11c). Part of the reason for this may have been the sedimentation of ice. However, this is in keeping with the better agreement with the $D 10$ scheme, since predicted IN concentrations in that scheme increase more much slowly with decreasing temperature compared to the other schemes that were considered (Fig. 10).

In contrast to the low concentrations observed at the heterogeneous ice nucleation temperatures, much larger ice concentrations were observed within the temperature range of the Hallett Mossop ice multiplication process $\left(-3\right.$ to $\left.-8^{\circ} \mathrm{C}\right)$. $60 \mathrm{~s}$ concentrations reached up to $6.261^{-1}$, values one or two orders of magnitude larger than those seen at much colder heterogeneous freezing temperatures. The difference between the ice concentrations observed in the two temperature zones is also evident in Fig. 11, which also clearly demonstrates that ice concentrations far higher than those predicted by $D 10$ were observed in the HM zone. CIP images revealed the presence of ice columns that are consistent with ice growth within the Hallett Mossop temperature range. Such differences are consistent with previous studies. For example, Crawford et al. (2012) showed that in the presence of drizzle droplets, secondary ice particle production by the Hallett-Mossop process was able to increase the ice crystal concentrations by up to 4 orders of magnitude in timescales of up to $40 \mathrm{~min}$. It has also been demonstrated here that the observed ice concentrations and droplet spectra are roughly consistent with the number of ice splinters produced by the riming of each large droplet $(D>25 \mu \mathrm{m})$ in the laboratory studies of Mossop (1985), if a reasonably high fraction of the large droplets were to freeze.

The contrast between Hallett Mossop zone ice concentrations and the fairly low concentrations of heterogeneously nucleated ice suggests that the Hallet Mossop process has the potential to be very important in remote, pristine regions by rapidly increasing the number of ice crystals to the point where they can impact both the water budget of the cloud (by initiating precipitation) and the cloud radiative properties. Thus, its representation in global models needs to be accurate.

However, the ubiquity of this process, even within liquid water containing regions within the right temperature range, is uncertain. In this study, the lack of detection of any ice in some such regions gives further evidence that the process requires additional conditions to be met before it can operate. The observations here indicated that, as well as the presence of a significant fraction of water droplets that are $>25 \mu \mathrm{m}$ (as previously demonstrated in laboratory studies, e.g. Mossop, 1985; Saunders and Hosseini, 2001), ice seeding through precipitation or advection from clouds at colder temperatures than those within the HM zone is required. The accurate representation of this in global models is likely to represent a challenge.

At present the lack of accurate in-situ measurements of simultaneous ice, droplet, IN and aerosol concentrations is a severe limiting factor for Antarctic cloud microphysical studies and this needs to be addressed in order for progress to be made.

\section{Appendix A}

\section{Further instrumentation details}

\section{A1 Changes made to the CIP shattering detection algorithm}

Some small modifications were made to the particle image rejection criteria in the CIP software compared that used in Crosier et al. (2011). The threshold for the number of secondary images (e.g. ice fragments, droplets, etc within the same particle image) allowed was increased from 3 to 10 , and the maximum total area allowed for secondary images was increased from $10 \%$ to $25 \%$ of the total particle image area. These changes were made as it was found that many larger ice particles were being rejected due to the presence of fragments that were very small relative to the ice particle. It should be noted that such fragment containing images are only counted as one particle by the software (i.e. the fragments are not counted). Inter-arrival time analysis (e.g. Field et al., 2006) was also used to identify and remove any artefacts.

\section{A2 CIP sampling considerations}

The effective sample volume within which a particle can be detected and counted by the CIP optical system, (and similar cloud imaging spectrometers), is a product of the distance moved by the aircraft and the so-called probe sample area, (SA). The SA is the product of the photo diode effective array width (EAW) and the depth of field (DOF). The DOF is a strongly increasing function of size up to particle diameters of $212 \mu \mathrm{m}$, above which it is constant. The particle size dependence of the EAW is discussed below.

In the analysis here we have used both the "all-in" and "centre-in" techniques when counting particles from the recorded images (see Heymsfield and Parrish, 1978) depending on the type/shape of particle. With the centre-in technique particles are included if their centres can be determined to be within the width of the diode array and the criteria for this follows that described by Heymsfield and Parrish (1978). The advantage of this technique is that, as long as particles are within the DOF, they have a roughly equal chance of being accepted based on their position parallel to the diode array, regardless of their size and thus the EAW is constant. Also, this technique allows a higher proportion of the imaged 
particles to be counted and hence better sampling statistics, which is particularly important in low concentration regions.

However, the technique of Heymsfield and Parrish (1978) has limitations when determining the diameter of nonspherical particles that touch at least one of the array edges since it assumes a circular 2-D projection of the particle. Thus when non-spherical large aspect ratio particles, such as columns, are present the "all-in" technique was used. This method rejects particles that touch any of the edges, which means that larger particles can be sampled over less of the length of the diode array and therefore have a smaller EAW (and hence smaller sample volume if everything else is constant).

The stronger size dependence of the sample volume with the all-in technique means that a larger number of particles need to be sampled in order to avoid statistical biases and to obtain an accurate representation of ice concentrations. In this study the presence of columns was always associated with well-developed Hallett-Mossop secondary ice multiplication zones and so particle numbers tended to be very high relative to other sampled cloud regions. The large number of particles imaged per sampling period therefore likely provided a good representation of the average EAW, and thus the sample area and concentration.

\section{Appendix B}

\section{The synoptic situation for the flights}

For the first flight (\#99) there was a low-pressure system to the west of the AP associated with a strong pressure gradient and with isobars aligned in the north-south direction. A high pressure system was present to the east over the Weddell Sea. Orographic cloud and a large area of cloud over the Larsen Ice Shelf was observed from satellite images at this time. For the flight conducted on the 8 February (\#100) the low pressure system to the east was still in place, but a warm front, lying east-west and with an associated band of cirrus cloud, had moved down the west coast of the AP. To the north of this there was some isolated cloud and a region of stratocumulus which was subsequently sampled by the aircraft. By the time of flight \#101 (9 February) the low pressure had moved towards S. America and a second system had formed to the NE of the AP peninsula. This resulted in strong easterlies along the ridge. A stationary occluded front lay along the east side of the ridge with thick extensive cloud (from $\sim 2000 \mathrm{~m}$ to near the surface) persisting over the Larsen Ice Shelf. The situation was similar for flight \#102 (11 February) with mainly high cirrus in the Rothera region. However, stacks of lenticular clouds had formed over the ridge and downwind of it, which were sampled by the aircraft.

By flight \#104 (12 February) a second centre of low pressure just to the west of the ridge had formed (Fig. 1). The old occluded front that had produced the deep cloud during flight \#101 had again become stationary along the east of the AP with extensive cloud covering the Larsen Ice Shelf. However, unlike the continuous cloud of flight \#101, the cloud now consisted of at least 3 thin layers.

Acknowledgements. We would like to sincerely thank Russell Ladkin, Tom Lachlan-Cope and all other members of the British Antarctic Survery (BAS) aircraft team for all their hard work in Antarctica. Many thanks also to Mike Flynn and James Dorsey for their help with instrument calibration. We also acknowledge funding support from the British Antarctic Survey. We would also like to thank the two anonymous reviewers for taking the time to read the manuscript and for providing valuable comments and suggestions.

Edited by: M. Krämer

\section{References}

Alpert, P. A., Aller, J. Y., and Knopf, D. A.: Initiation of the ice phase by marine biogenic surfaces in supersaturated gas and supercooled aqueous phases, Phys. Chem. Chem. Phys., 13, 19882-19894, doi:10.1039/c1cp21844a, 2011.

Ardon-Dryer, K., Levin, Z., and Lawson, R. P.: Characteristics of immersion freezing nuclei at the South Pole station in Antarctica, Atmos. Chem. Phys., 11, 4015-4024, doi:10.5194/acp-11-40152011, 2011.

Avramov, A., Ackerman, A. S., Fridlind, A. M., van Diedenhoven, B., Botta, G., Aydin, K., Verlinde, J., Korolev, A. V., Strapp, J. W., McFarquhar, G. M., Jackson, R., Brooks, S. D., Glen, A., and Wolde, M.: Toward ice formation closure in Arctic mixedphase boundary layer clouds during ISDAC, J. Geophys. Res., 116, D00T08, doi:10.1029/2011JD015910, 2011.

Barbante, C., Turetta, C., Gambaro, A., Capodaglio, G., and Scarponi, G.: Sources and origins of aerosols reaching Antarctica as revealed by lead concentration profiles in shallow snow, in: Annals of Glaciology, Vol. 27, 674-678, 1998, edited by: Budd, W. F., Cooperative Res Ctr Antarctica; SO Ocean (Antarctic CRC); Australian Antarctic Div; Int Glaciol Soc; Global Change \& Antarctic program of SCAR, International Symposium on Antarctica and Global Change - Interactions and Impacts, Hobart, Australia, 13-18 July 1997, 1998.

Baumgardner, D., Jonsson, H., Dawson, W., O'Connor, D., and Newton, R.: The cloud, aerosol and precipitation spectrometer: a new instrument for cloud investigations, Atmospheric Research, 59, 251-264, doi:10.1016/S0169-8095(01)00119-3, 13th International Conference on Clouds and Precipitation, Desert Res. Inst., Reno, Nevada, 14-17 August 2000, 2001.

Bigg, E. K.: Long-term trends in ice nucleus concentrations, Atmos. Res., 25, 409-415, 1990.

Bromwich, D. H., Nicolas, J. P., Hines, K. M., Kay, J. E., Key, E. L., Lazzara, M. A., Lubin, D., McFarquhar, G. M., Gorodetskaya, I. V., Grosvenor, D. P., Lachlan-Cope, T., and van Lipzig, N. P. M.: Tropospheric clouds in antarctica, Rev. Geophys., 50, RG1004, doi:10.1029/2011RG000363, 2012.

Christner, B. C., Morris, C. E., Foreman, C. M., Cai, R., and Sands, D. C.: Ubiquity of biological ice nucleators in snowfall, Science, 319, 1214, doi:10.1126/science.1149757, 2008. 
Cober, S., Strapp, J., and Isaac, G.: An example of supercooled drizzle drops formed through a collision-coalescence process, J. Appl. Meteorol., 35, 2250-2260, doi:10.1175/15200450(1996)035<2250:AEOSDD>2.0.CO;2, 1996.

Cooper, W.: Ice Initiation in Natural Clouds. Precipitation Enhancement - A Scientific Challenge, Meteorological. Monographs, 21, 29-32, 1986.

Crawford, I., Bower, K. N., Choularton, T. W., Dearden, C., Crosier, J., Westbrook, C., Capes, G., Coe, H., Connolly, P. J., Dorsey, J. R., Gallagher, M. W., Williams, P., Trembath, J., Cui, Z., and Blyth, A.: Ice formation and development in aged, wintertime cumulus over the UK: observations and modelling, Atmos. Chem. Phys., 12, 4963-4985, doi:10.5194/acp-12-4963-2012, 2012.

Crosier, J., Bower, K. N., Choularton, T. W., Westbrook, C. D., Connolly, P. J., Cui, Z. Q., Crawford, I. P., Capes, G. L., Coe, H., Dorsey, J. R., Williams, P. I., Illingworth, A. J., Gallagher, M. W., and Blyth, A. M.: Observations of ice multiplication in a weakly convective cell embedded in supercooled mid-level stratus, Atmos. Chem. Phys., 11, 257-273, doi:10.5194/acp-11-257-2011, 2011.

DeMott, P., Cziczo, D., Prenni, A., Murphy, D., Kreidenweis, S., Thomson, D., Borys, R., and Rogers, D.: Measurements of the concentration and composition of nuclei for cirrus formation, P. Natl. Acad. Sci. USA, 100, 14655-14660, doi:10.1073/pnas.2532677100, 2003.

DeMott, P. J., Prenni, A. J., Liu, X., Kreidenweis, S. M., Petters, M. D., Twohy, C. H., Richardson, M. S., Eidhammer, T., and Rogers, D. C.: Predicting global atmospheric ice nuclei distributions and their impacts on climate, P. Natl. Acad. Sci. USA, 107, 11217-11222, doi:10.1073/pnas.0910818107, 2010.

DeMott, P. J., Moehler, O., Stetzer, O., Vali, G., Levin, Z., Petters, M. D., Murakami, M., Leisner, T., Bundke, U., Klein, H., Kanji, Z. A., Cotton, R., Jones, H., Benz, S., Brinkmann, M., Rzesanke, D., Saathoff, H., Nicolet, M., Saito, A., Nillius, B., Bingemer, H., Abbatt, J., Ardon, K., Ganor, E., Georgakopoulos, D. G., and Saunders, C.: Resurgence in ice nuclei measurement research, B. Am. Meteorol. Soc., 92, 1623-1635, doi:10.1175/2011BAMS3119.1, 2011.

DMT: CIP Manual, DOC-0028, Rev K-1, Tech. rep., Droplet Measurement Technologies, http://www.dropletmeasurement.com/ resources/manuals-and-guides.html, 2011.

Fiebig, M., Lunder, C. R., and Stohl, A.: Tracing biomass burning aerosol from South America to Troll Research Station, Antarctica, Geophys. Res. Lett., 36, L14815, doi:10.1029/2009GL038531, 2009.

Field, P. R., Heymsfield, A. J., and Bansemer, A.: Shattering and particle interarrival times measured by optical array probes in ice clouds, J. Atmos. Ocean. Technol., 23, 1357-1371, doi:10.1175/JTECH1922.1, 2006.

Fletcher, N. H.: Physics of Rain Clouds, Cambridge University Press, 1962.

Fridlind, A. M., Ackerman, A. S., McFarquhar, G., Zhang, G., Poellot, M. R., DeMott, P. J., Prenni, A. J., and Heymsfield, A. J.: Ice properties of single-layer stratocumulus during the Mixed-Phase Arctic Cloud Experiment: 2. Model results, J. Geophys. Res.Atmos., 112, D24202, doi:10.1029/2007JD008646, 2007.

Hallett, J. and Mossop, S.: Production of secondary ice particles during the riming process, Nature, 249, 26-28, doi:10.1038/249026a0, 1974.
Hara, K., Osada, K., Yabuki, M., Hashida, G., Yamanouchi, T., Hayashi, M., Shiobara, M., Nishita, C., and Wada, M.: Haze episodes at Syowa Station, coastal Antarctica: Where did they come from?, J. Geophys. Res.-Atmos., 115, D14205, doi:10.1029/2009JD012582, 2010.

Hara, K., Osada, K., Nishita-Hara, C., Yabuki, M., Hayashi, M., Yamanouchi, T., Wada, M., and Shiobara, M.: Seasonal features of ultrafine particle volatility in the coastal Antarctic troposphere, Atmos. Chem. Phys., 11, 9803-9812, doi:10.5194/acp-11-98032011, 2011.

Heymsfield, A. and Parrish, J.: A computational technique for increasing the effective sampling volume of the PMS twodimensional particle size spectrometer, J. Appl. Meteorol., 17, 1566-1572, 1978.

Heymsfield, A. J., Kennedy, P. C., Massie, S., Schmitt, C., Wang, Z., Haimov, S., and Rangno, A.: Aircraft-induced hole punch and canal clouds. Inadvertent Cloud Seeding, B. Am. Meteorol. Soc., 91, 753-766, doi:10.1175/2009BAMS2905.1, 2010.

Hogan, A.: Aerosol exchange in the remote troposphere, Tellus B, 38, 197-213, 1986.

Hoose, C., Kristjansson, J. E., and Burrows, S. M.: How important is biological ice nucleation in clouds on a global scale?, Environ. Res. Lett., 5, 024009, doi:10.1088/1748-9326/5/2/024009, 2010.

Huffman, G. and Norman, G.: The supercooled warm rain process and the specification of freezing precipitation, Mon. Weather Rev., 116, 2172-2182, doi:10.1175/15200493(1988)116<2172:TSWRPA>2.0.CO;2, 1988.

Junge, K. and Swanson, B. D.: High-resolution ice nucleation spectra of sea-ice bacteria: implications for cloud formation and life in frozen environments, Biogeosciences, 5, 865-873, doi:10.5194/bg-5-865-2008, 2008.

Kajikawa, M., Kikuchi, K., Asuma, Y., Inoue, Y., and Sato, N.: Supercooled drizzle formed by condensation-coalescence in the mid-winter season of the Canadian Arctic, Atmos. Res., 52, 293 301, doi:10.1016/S0169-8095(99)00035-6, 2000.

Kay, J. E., Hillman, B. R., Klein, S. A., Zhang, Y., Medeiros, B., Pincus, R., Gettelman, A., Eaton, B., Boyle, J., Marchand, R., and Ackerman, T. P.: Exposing Global Cloud Biases in the Community Atmosphere Model (CAM) Using Satellite Observations and Their Corresponding Instrument Simulators, J. Climate, 25, 5190-5207, doi:10.1175/JCLI-D-11-00469.1, 2012.

King, J. C., Lachlan-Cope, T. A., Ladkin, R. S., and Weiss, A.: Airborne measurements in the stable boundary layer over the Larsen Ice Shelf, Antarctica, Bound.-Lay. Meteorol., 127, 413428, doi:10.1007/s10546-008-9271-4, 2008.

Knopf, D. A., Alpert, P. A., Wang, B., and Aller, J. Y.: Stimulation of ice nucleation by marine diatoms, Nat. Geosci., 4, 88-90, doi:10.1038/NGEO1037, 2011.

Korolev, A. V., Emery, E. F., Strapp, J. W., Cober, S. G., Isaac, G. A., Wasey, M., and Marcotte, D.: Small Ice Particles in Tropospheric Clouds: Fact or Artifact? Airborne Icing Instrumentation Evaluation Experiment, B. Am. Meteorol. Soc., 92, 967973, doi:10.1175/2010BAMS3141.1, 2011.

Kuipers Munneke, P., van den Broeke, M. R., King, J. C., Gray, T., and Reijmer, C. H.: Near-surface climate and surface energy budget of Larsen C ice shelf, Antarctic Peninsula, The Cryosphere, 6, 353-363, doi:10.5194/tc-6-353-2012, 2012.

Kumai, M.: Identification of nuclei and concentrations of chemical species in snow crystals sampled at 
south-pole, J. Atmos. Sci., 33, 833-841, doi:10.1175/15200469(1976)033<0833:IONACO > 2.0.CO;2, 1976.

Lachlan-Cope, T., Ladkin, R., Turner, J., and Davison, P.: Observations of cloud and precipitation particles on the Avery Plateau, Antarctic Peninsula, Antarct. Sci., 13, 339-348, 2001.

Lubin, D., Chen, B., Bromwich, D., Somerville, R., Lee, W., and Hines, K.: The impact of Antarctic cloud radiative properties on a GCM climate simulation, J. Climate, 11, 447-462, doi:10.1175/1520-0442(1998)011<0447:TIOACR > 2.0.CO;2, 1998.

McConnell, J. R., Aristarain, A. J., Banta, J. R., Edwards, P. R., and Simoes, J. C.: 20th-Century doubling in dust archived in an Antarctic Peninsula ice core parallels climate change and desertification in South America, P. Natl. Acad. Sci. USA, 104, 57435748, doi:10.1073/pnas.0607657104, 2007.

Meyers, M., DeMott, P., and Cotton, W.: New primary icenucleation parameterizations in an explicit cloud model, J. Appl. Meteorol., 31, 708-721, doi:10.1175/15200450(1992)031<0708:NPINPI>2.0.CO;2, 1992.

Mitchell, D. and Heymsfield, A.: Refinements in the treatment of ice particle terminal velocities, highlighting aggregates, J. Atmos. Sci., 62, 1637-1644, doi:10.1175/JAS3413.1, 2005.

Möhler, O., DeMott, P. J., Vali, G., and Levin, Z.: Microbiology and atmospheric processes: the role of biological particles in cloud physics, Biogeosciences, 4, 1059-1071, doi:10.5194/bg-4-10592007, 2007.

Morrison, H., Thompson, G., and Tatarskii, V.: Impact of Cloud Microphysics on the Development of Trailing Stratiform Precipitation in a Simulated Squall Line: Comparison of One- and Two-Moment Schemes, Mon. Weather Rev., 137, 991-1007, doi:10.1175/2008MWR2556.1, 2009.

Mossop, S.: Secondary ice particle-production during rime growth - the effect of drop size distribution and rimer velocity, Q. J. Roy. Meteor. Soc., 111, 1113-1124, doi:10.1002/qj.49711147012, 1985.

O'Dowd, C., Smith, M., Consterdine, I., and Lowe, J.: Marine aerosol, sea-salt, and the marine sulphur cycle: A short review, Atmos. Environ., 31, 73-80, 1997.
Painemal, D. and Zuidema, P.: Assessment of MODIS cloud effective radius and optical thickness retrievals over the Southeast Pacific with VOCALS-REx in situ measurements, J. Geophys. Res.-Atmos., 116, D24206, doi:10.1029/2011JD016155, 2011.

Pavolonis, M. and Key, J.: Antarctic cloud radiative forcing at the surface estimated from the AVHRR Polar Pathfinder and ISCCP D1 datasets, 1985-93, J. Appl. Meteorol., 42, 827-840, doi:10.1175/1520-0450(2003)042<0827:ACRFAT>2.0.CO;2, 2003.

Pruppacher, H. R. and Klett, J. D.: Microphysics of clouds and precipitation, Kluwer Academic Press, Dordrecht/Boston/London, 1997.

Saunders, C. and Hosseini, A.: A laboratory study of the effect of velocity on Hallett-Mossop ice crystal multiplication, Atmospheric Research, 59, 3-14, doi:10.1016/S0169-8095(01)001065, 13th International Conference on Clouds and Precipitation, Desert Res. Inst., Reno, Nevada, 14-17 August 2000, 2001.

Saxena, V. K. and Ruggiero, F. H.: Antarctic coastal stratus clouds: Microstructure and acidity, Contributions to Antarctic Research I, Antarctic Research Series, AGU, Washington D.C., 50, 7-18, 1990.

Scambos, T., Hulbe, C., Fahnestock, M., and Bohlander, J.: The link between climate warming and break-up of ice shelves in the Antarctic Peninsula, J. Glaciol., 46, 516-530, doi:10.3189/172756500781833043, 2000.

Scambos, T., Bohlander, J., Shuman, C., and Skvarca, P.: Glacier acceleration and thinning after ice shelf collapse in the Larsen B embayment, Antarctica, Geophys. Res. Lett., 31, L18402, doi:10.1029/2004GL020670, 2004.

Shupe, M. and Intrieri, J.: Cloud radiative forcing of the Arctic surface: The influence of cloud properties, surface albedo, and solar zenith angle, J. Climate, 17, 616-628, doi:10.1175/15200442(2004)017<0616:CRFOTA>2.0.CO;2, 2004.

van den Broeke, M.: Strong surface melting preceded collapse of Antarctic Peninsula ice shelf, Geophys. Res. Lett., 32, L12815, doi:10.1029/2005GL023247, 2005.

Westbrook, C. and Davies, O.: Observations of a glaciating holepunch cloud, Weather, 65, 176-180, doi:10.1002/wea.504, 2010. 